\title{
Recent Progress in the Development of Graphene Detector for Terahertz Detection
}

\author{
Jianlong Liu ${ }^{1}$, Xin Li ${ }^{1}$, Ruirui Jiang ${ }^{1}$, Kaiqiang Yang ${ }^{1}$, Jing Zhao ${ }^{1}$, Sayed Ali Khan ${ }^{2}$, Jiancheng He ${ }^{1}$, \\ Peizhong Liu ${ }^{3}$, Jinfeng Zhu ${ }^{2, *}$ and Baoqing Zeng ${ }^{1}$
}

1 National Key Laboratory of Science and Technology on Vacuum Electronics, School of Electronic Science and Engineering, University of Electronic Science and Technology of China, Chengdu 610054, China; liujianlong@uestc.edu.cn (J.L.); 201922021527@std.uestc.edu.cn (X.L.); 201711040120@std.uestc.edu.cn (R.J.); 201811022515@std.uestc.edu.cn (K.Y.); 202011022910@std.uestc.edu.cn (J.Z.); 201921020407@std.uestc.edu.cn (J.H.); bqzeng@uestc.edu.cn (B.Z.)

2 Institute of Electromagnetics and Acoustics, School of Electronic Science and Engineering, Xiamen University, Xiamen 361005, China; sayedali@mail.ustc.edu.cn

3 Department of the Internet of Things Engineering, College of Engineering, Huaqiao University, Quanzhou 362000, China; pzliu@hqu.edu.cn

* Correspondence: jfzhu@xmu.edu.cn

check for updates

Citation: Liu, J.; Li, X.; Jiang, R.; Yang, K.; Zhao, J.; Khan, S.A.; He, J.; Liu, P.; Zhu, J.; Zeng, B. Recent Progress in the Development of Graphene Detector for Terahertz Detection. Sensors 2021, 21, 4987. https://doi.org/10.3390/s21154987

Academic Editor: Gintaras Valusis

Received: 10 June 2021

Accepted: 19 July 2021

Published: 22 July 2021

Publisher's Note: MDPI stays neutral with regard to jurisdictional claims in published maps and institutional affiliations.

Copyright: (C) 2021 by the authors. Licensee MDPI, Basel, Switzerland. This article is an open access article distributed under the terms and conditions of the Creative Commons Attribution (CC BY) license (https:/ / creativecommons.org/licenses/by/ $4.0 /)$.

\begin{abstract}
Terahertz waves are expected to be used in next-generation communications, detection, and other fields due to their unique characteristics. As a basic part of the terahertz application system, the terahertz detector plays a key role in terahertz technology. Due to the two-dimensional structure, graphene has unique characteristics features, such as exceptionally high electron mobility, zero band-gap, and frequency-independent spectral absorption, particularly in the terahertz region, making it a suitable material for terahertz detectors. In this review, the recent progress of graphene terahertz detectors related to photovoltaic effect (PV), photothermoelectric effect (PTE), bolometric effect, and plasma wave resonance are introduced and discussed.
\end{abstract}

Keywords: graphene; terahertz detector; photovoltaic effect; photothermoelectric effect; plasma wave resonance

\section{Introduction}

The terahertz $(\mathrm{THz})$ wave is an electromagnetic wave in a particular band having a frequency range of $0.1-10 \mathrm{THz}$ (wavelength within 30-3000 microns) [1]. This frequency band is within the electronics-to-photonics transition region, and it leads the $\mathrm{THz}$ waves to have certain characteristics of the microwaves and the light waves. Comparing with the microwaves and millimeter waves, the $\mathrm{THz}$ imaging system is capable of a higher resolution in detection and imaging [2]. More interestingly, $\mathrm{THz}$ waves penetrate dust and smoke more easily than infrared and visible light, making them ideal for working in harsh environments [3-5]. Furthermore, $\mathrm{THz}$ waves often have a strong capacity to penetrate nonpolar materials, such as leather and plastics, and they are capable of effectively detecting concealed hazardous items, such as explosives, drugs, and firearms along with other prohibited objects, which make the $\mathrm{THz}$ waves important for applications in security [6-8]. The $\mathrm{THz}$ waves are also suitable for biomedical imaging and medical diagnosis of various diseases due to their low energy photons compared to X-rays, which do not cause any adverse effects of photoionization on biological tissues $[9,10]$.

The $\mathrm{THz}$ detectors mainly include bolometer, pyroelectric detector, Golay cell, Schottky diode detector, nanometric field-effect transistor (NFET), etc. [11]. The bolometer relies on temperature-related resistance. When the $\mathrm{THz}$ wave radiates to the working area, the resistance of the thermistor will change. This change can reflect the radiation intensity of terahertz [12-14]. This kind of detector usually works at low temperatures, which needs to be equipped with refrigeration equipment [15]. The pyroelectric detector operates via the 
pyroelectric effect of the crystal. Owing to the absorption of THz waves, the temperature of the crystal increases and cause a change of carrier concentration. A potential difference is formed at both ends of the crystal, and the energy of the THz wave can be calculated according to the magnitude of the potential difference, and the potential difference will disappear when the internal temperature of the crystal is balanced [16-18]. The working principle of the Golay cell detector is that the gas absorbs energy and expands as the $\mathrm{THz}$ wave irradiates the gas cavity, causing deformation of the film in the cavity, and the identification of the $\mathrm{THz}$ wave can be accomplished by calculating the deformity [19]. The Schottky diode detector is made of a Schottky diode between the metal and semiconductor. This kind of detector usually working at room temperature (RT) [20-22]. The NFET mainly uses the plasma wave excited in the channel of the device to detect the $\mathrm{THz}$ wave. Since the excitation of the plasma wave requires only a small amount of energy, this detector has high responsiveness [23]. The device is small in size and easy to integrate [24]. In addition, there is research on using bow-tie diodes made of $\mathrm{GaAs}$ or InGaAs to detect $\mathrm{THz}$ waves [25-27]. The working parameters of these detectors are shown in Table 1, and the digital photographs of these detectors are depicted in Figure 1.

Table 1. Performance parameters of terahertz detectors.

\begin{tabular}{ccccc}
\hline Type & Response Time & Frequency Range & $\begin{array}{c}\text { Noise-Equivalent } \\
\text { Power (NEP) }\end{array}$ & Reference \\
\hline Bolometer & $10 \mu \mathrm{s}$ & - & $10^{-9} \mathrm{~W} / \mathrm{Hz}^{1 / 2}$ & {$[20,28]$} \\
$\begin{array}{c}\text { Pyroelectric } \\
\text { detector }\end{array}$ & less than $10 \mathrm{~ms}$ & $0.1-30 \mathrm{THz}$ & $10^{-10} \mathrm{~W} / \mathrm{Hz}^{1 / 2}$ & {$[17,29]$} \\
Golay cell & $10 \mathrm{~ms}$ & $0.1-20 \mathrm{THz}$ & $10^{-10} \mathrm{~W} / \mathrm{Hz}^{1 / 2}$ & {$[30]$} \\
Schottky diode & $100 \mathrm{ps}$ & $0.1-1.7 \mathrm{THz}$ & $10^{-10} \mathrm{~W} / \mathrm{Hz}^{1 / 2}$ & {$[20,22]$} \\
NFET & less than $30 \mathrm{ps}$ & $0.3-4.9 \mathrm{THz}$ & $10^{-12} \mathrm{~W} / \mathrm{Hz}^{1 / 2}$ & {$[24,31,32]$} \\
Bow-tie diode & $7 \mathrm{~ns}$ & $0.1-2.5 \mathrm{THz}$ & $10^{-9} \mathrm{~W} / \mathrm{Hz}^{1 / 2}$ & {$[25-27]$} \\
\hline
\end{tabular}

a
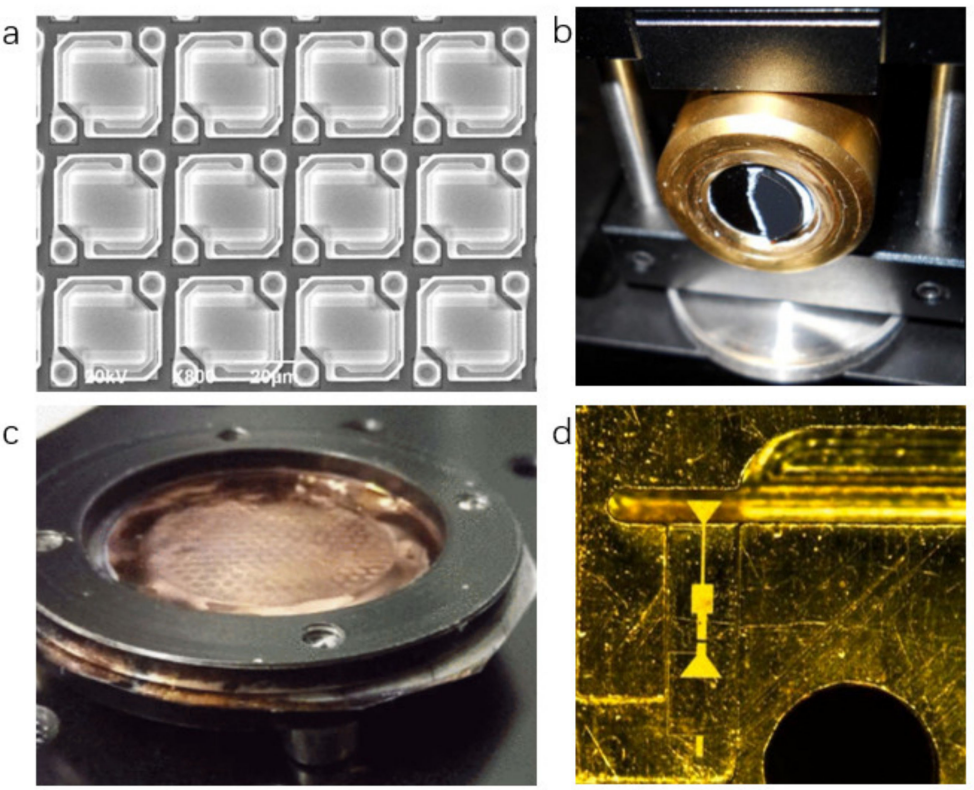

Figure 1. (a) The image of Bolometer array. Reprinted with permission from ref. [33]. Copyright 1969 Elsevier. (b) Appearance of pyroelectric detector. Reprinted with permission from ref. [34]. Copyright 2021 Copyright Clearance Center. (c) Appearance of Golay cell. Reprinted with permission from ref. [35]. Copyright 2021 Copyright Clearance Center. (d) Photograph of Schottky diode. Reprinted with permission from ref. [36]. Copyright 2021 Copyright Clearance Center.

The nature of the materials and their structures have a significant impact on the performance $\mathrm{THz}$ detector [37]. For example, the mobility of the materials used in the 
$\mathrm{THz}$ detector has a direct impact on their sensitivity. More specifically, when the material mobility is high enough, the device can induce resonant surface plasma oscillations in the channel, which can dramatically reduce the noise equivalence power (NEP). With the advancement of material, two-dimensional (2D) materials with excellent photoelectric properties have been produced and applied to $\mathrm{THz}$ detectors such as graphene, black phosphorus, and transition metal dichalcogenides [38,39].

It had been Geim and Novoselov, who used mechanical exfoliation to develop graphene, a single-atomic-layer graphite structure [40]. Graphene is a 2D material with a hexagonal honeycomb lattice composed of carbon atoms and sp2 hybrid orbitals [41]. The arrangement of carbon atoms in graphene determines its unique conical band structure, which makes graphene have some unique properties, including a quantum Hall effect at room temperature, adjustable conductivity, small carrier equivalent mass, very large mean free path, etc. [42,43]. Moreover, graphene has a theoretical value of intrinsic electron mobility up to $200,000 \mathrm{~cm}^{2} / \mathrm{V} \cdot \mathrm{s}$ at room temperature, which is 140 times greater than silicon. In addition, a stable atomic structure with only weak van der Waals forces at the interface makes it favorable for other materials to form a heterostructure $[42,44,45]$. The graphene has great application potential in various fields such as NFET, nano-electronic devices, highsensitivity sensors, etc. [46-48]. The 2D planar structure composed of the atomic layers can be regarded as the thinnest two-dimensional electron gas. The high carrier mobility, adjustable conductivity, and other promising characteristics make graphene a novel material for far-infrared radiation (FIR) and THz devices, especially novel photodetectors [49].

\section{Classification of Graphene Terahertz Detectors}

The most commonly used $\mathrm{THz}$ detectors have some limitations for specific applications. For example, the response speed of the pyroelectric detectors and Golay cell is low, and it is difficult to respond in real time to ultra-short $\mathrm{THz}$ pulse signals in the order of picoseconds $[17,50]$. Schottky diode detectors can only have good responsivity below $1 \mathrm{THz}$ due to their parasitic parameters but have lower damage threshold energy, which makes it difficult to resist the powerful electric field of terahertz irradiation and easy to be damaged in practical applications. Graphene has a unique zero bandgap structure with exceptionally high carrier mobility and can be modified for conductivity; those excellent features make it an ideal material for making $\mathrm{THz}$ detectors [51-54]. The THz detectors fabricated with graphene boost the working frequency of the device by efficiently reducing the impact of major noise sources of the high-frequency range transistor, effectively lowering the noise of the high-frequency devices. The working principle of a graphene detector mainly includes the photovoltaic effect (PV), photoconductivity effect, photo-thermoelectric effect (PTE), bolometer effect, plasma wave resonance, etc. Among these working principles, some of them change the conductivity after absorbing radiation, and a bias voltage is needed to detect this change. Others generate photocurrent by themselves after absorbing radiation, and this kind of detector does not require a bias voltage. According to this characteristic, we divide graphene $\mathrm{THz}$ detectors into two categories.

\subsection{Non-Zero Bias Detectors}

In general, most of the graphene non-zero bias detectors are graphene bolometers. A bolometer is a device that uses the bolometer effect to detect the intensity of the radiation power. The bolometer is based on an electrical resistance's temperature dependency. More specifically, the working mechanism of the bolometer is to convert absorbed terahertz radiation energy to a changing temperature value by absorbing a photon and increasing the electron temperature from $\mathrm{T}_{0}$ to $\mathrm{T}_{\text {peak, }}$, as illustrated in Figure $2 \mathrm{a}$, causing a change in the thermosensitive resistance of materials. To measure terahertz radiation, a bias voltage needs to be added to the device, and the current increases linearly with the voltage. The thermal resistance and the heat capacity are the key parameters of the device, as illustrated in Figure $2 b[55,56]$. Notably, the electron heat capacity in graphene is small, and the 
electron-phonon coupling is weak $[57,58]$. These advantages are very suitable for making a thermal detector with fast response time, higher sensitivity, and less noise.

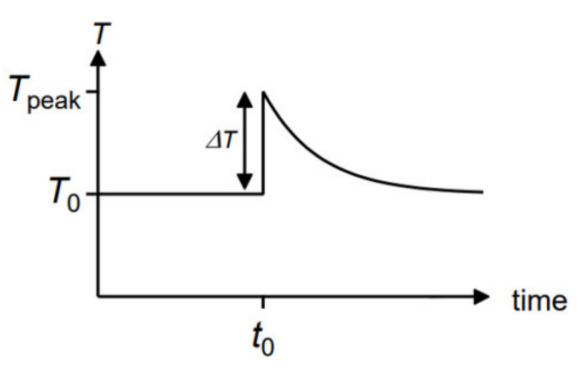

(a)

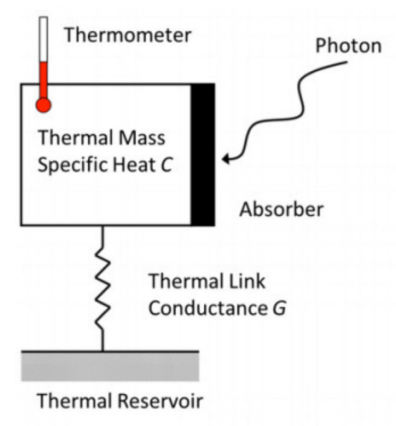

(b)

Figure 2. (a) The temperature response $\mathrm{T}(\mathrm{t})$ for a calorimeter. (b) Schematic illustration of bolometer working principle in a graphene detector, $\mathrm{C}$ (heat capacity) and the thermometer function are provided by the electron subsystem. $G$ (thermal conductance) is provided by the coupling to the contacts and substrate as well as emitted Johnson noise. Reprinted with permission from ref. [56]. Copyright 2021 Copyright Clearance Center.

Ryzhii et al. [59] report a bolometer theoretical model with bilayer graphene. One layer of graphene is doped n-type, and the other layer is doped p-type. Both of them are connected by an array of undoped graphene nano-ribbons (GNRs). The graphene layer absorbs $\mathrm{THz}$ radiation, and the GNR array acts as a barrier area. The computational analysis validates that the voltage response of this structure's bolometer can reach $1 \times 10^{5} \mathrm{~V} / \mathrm{W}$, indicating that it has superior performance parameters compared to the bolometers discussed previously [28]. This work provides a theoretical basis for the fabrication of a graphene bolometer.

Yan et al. [57] designed a bolometer that uses 2D graphene bulk instead of a onedimensional rectifying interface. The poor interaction between electrons and phonons within the graphene would create a bottleneck in the thermal direction of decoupling electrons thermally from the photonic bath after absorbing $\mathrm{THz}$ radiation. They used the non-linear nature of the light response to measure the response speed of the bolometer under different laser sources. The response curve is consistent with the bolometric model. The time average signal of the detector is determined by the slowest scattering process, while the fast scattering process does not contribute much. They considered thermal noise and Johnson-Nyquist noise when measuring progressive NEP; the response time is $1.2 \mathrm{~ms}$ at $4.2 \mathrm{~K}$ temperature, and NEP is as low as $1.2 \times 10^{-13} \mathrm{~W} / \mathrm{Hz}^{1 / 2}$. Under the assumption of a $\mathrm{T}^{-3}$ dependence of thermal resistance $\mathrm{R}_{\mathrm{h}}$ and a linear $\mathrm{T}$ dependence of the specific heat, the detector can have better performance at a lower temperature $\left(1.5 \times 10^{-20} \mathrm{~W} / \mathrm{Hz}^{1 / 2}\right.$ at $100 \mathrm{mK}$ with a response time of $3 \mu \mathrm{s})$. Reducing the volume of the detector can reduce the heat capacity and improve the sensitivity, which suggested that there is a big improvement needed in the future.

The conventional approach of using electrical transport as a readout detector can hardly realize the supervisory characteristic of graphene for making high-sensitivity $\mathrm{THz}$ detectors. A thermionic electron detector based on noise readout also has been reported [60]. The temperature of the thermionic electrons is determined by monitoring the thermal noise power of the detector as well as the temperature change caused by the incident wave. In the state of thermal equilibrium, the electron follows the Fermi-Dirac distribution in the quantum state. Electron absorption will more aggressively absorb energy since the temperature increases, and the possibility of energy levels being occupied by electrons above the Fermi level will increase. The absorbed $\mathrm{THz}$ radiation can cause the temperature change of electrons in the material; then, electron transfer and energy band change occurred [61-64]. 
With very weak coupling and high-speed thermal response, graphene could act as a highly sensitive bolometer. Fong et al. [65] introduced microwave frequency noise thermometry to study these delicate and wide-bandwidth thermal features. The measurement on the graphene sample is to provide a thermal conductance channel for cooling through the emission of photons into the measurement channel. This Johnson noise-based method can reach the thermodynamic limit. The measurement results are related to the theory of the electron-phonon coupling, which shows that the measurement of $\mathrm{THz}$ wave with noise in a low-temperature environment is a relatively ideal method. They used the fabricated bolometer to realize the heat capacity of a two-dimensional electron gas at zero fields.

Miao et al. [66] reported a graphene-based thermal noise readout bolometer. The detector is composed of graphene and a $\mathrm{THz}$ spiral metal antenna. The bolometer is a graphene micro-bridge connected to the logarithmic spiral antenna through Au contact. The detector had a THz response with the band range from 0.3 to $1.6 \mathrm{THz}$, and the NEP is $5.6 \times 10^{-12} \mathrm{~W} / \mathrm{Hz}^{1 / 2}$ at a temperature of $3 \mathrm{~K}$. Figure 3 a shows the structure, and Figure $3 \mathrm{~b}$ is the system test diagram of the detector. In order to understand the heat transfer of graphene microbridges, they measured three kinds of microbridge length (from 0.6 to $8 \mu \mathrm{m})$ and measure the detectors at different temperatures. The results illustrate that the length of the graphene microbridge has little influence on the NEP, but it is largely affected by the heat diffusion of the contact pad because of the electron diffusion. Using superconducting contact pads can improve the performance of the bolometer.

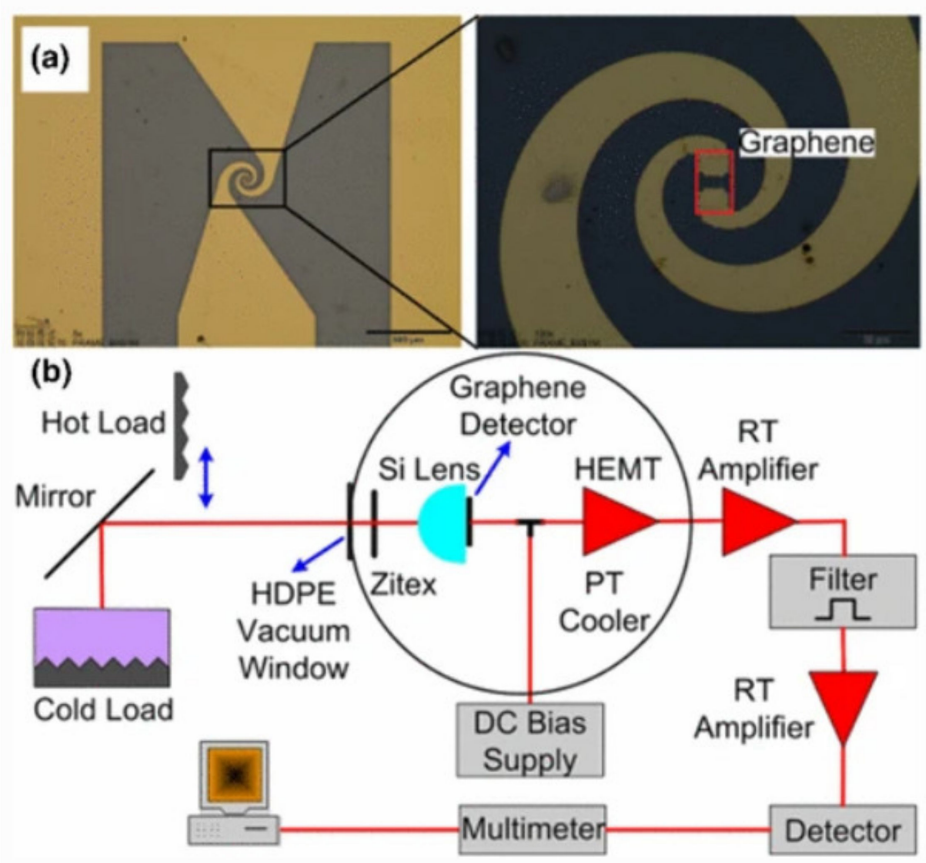

Figure 3. (a) Image of the graphene-based thermal noise readout bolometer. (b) The schematic illustration of the measurement system. Reprinted with permission from ref. [66]. Copyright 2021 Copyright Clearance Center.

\subsection{Zero-Bias Detectors}

In graphene zero-bias detectors, a built-in electric field is formed inside the material after absorbing $\mathrm{THz}$ radiation, so it can realize zero-bias detection. The built-in electric field can be enhanced by local mixing or the use of contact asymmetry. The working principle of graphene zero-bias detector mainly includes a photovoltaic effect, photo-thermoelectric effect, plasma wave resonance, etc. $[67,68]$. Compared with conventional photodetectors, such as GaAs/AlGaAs devices, graphene-based detectors have a wider detection wave range and faster response speed [69]. In theory, an antenna-coupled $\mathrm{THz}$ detector made by graphene with mobility of $1500 \mathrm{~cm}^{2} / \mathrm{V} \cdot \mathrm{s}$ can achieve A/W-level current responsivity and 
the NEP below $50 \mathrm{pW} / \mathrm{Hz}^{1 / 2}$ [70]. According to the different dominant mechanisms of photocurrent generation, we can divide these zero-bias detectors into two categories: one is the detector with PTE or PV, and the other is the detector with plasma wave resonance.

\subsubsection{The Detector Based on Photovoltaic Effect or Photothermoelectric Effect}

The detection mechanism of the photovoltaic effect means that when electromagnetic waves are irradiated on the detector, the electrons in the valence band of the photoelectric material absorb the energy according to the equation of $\mathrm{E}=\mathrm{h} v$ ( $\mathrm{h}$ is Planck constant and $v$ is frequency) of the photon, which leads to excite an electron to the conduction band of the high-energy state and leave a hole in the valence band of the low-energy state. The photogenerated electron-hole pairs are separated by the built-in electric field and form a photogenerated electric field opposite to the built-in electric field. The mechanism of the photothermoelectric effect is that when the photothermal material absorbs photons, the internal lattice vibration accelerated, and the temperature rises. The heat makes a part of the detector higher than the ambient temperature, which can make a temperature gradient inside the material. As a result, carrier concentrations between the hot and cold ends are different, which drives the multi-carriers in the hot end of the material to move to the cold end of the material and form a thermoelectric voltage $\mathrm{V}_{\mathrm{PTE}}=\left(\mathrm{S}_{1}-\mathrm{S}_{2}\right) \Delta \mathrm{T}$, where $\Delta \mathrm{T}$ is temperature difference and $S$ are Seebeck coefficients that are related to the conductivity. Fast photoelectric conversion can be realized due to the ultra-fast change of graphene conductivity with the radiation.

The photodetector usually combines the effect of the PV and the PTE, but their role during the detection can be far different [71,72]. Degl et al. [73] reported a THz detector with a graphene coupled antenna which is based on the photovoltaic effect. In order to improve the responsiveness and coupling of incident light to the detector, they used two different metals to make an antenna array. As illustrated in Figure 4a, one side of the antenna is built of Ti/Au to achieve n-type doping in nearby graphene, while the other is made of $\mathrm{Pd} / \mathrm{Au}$ to achieve p-type doping. As a result of the photovoltaic effect, they built an electric field at a metal-graphene junction, which separates the photo-excited electronhole pairs. There are multiple changes in the direction of the photocurrent generated by PTE in graphene because the Fermi energy is varied along the Dirac cone. The photocurrent in different back-gate voltages cannot be reversed, as shown in Figure $4 b$, which suggests that the photovoltaic effect dominates the detector. They also integrate the detector into the imaging system and receive $\mathrm{THz}$ imaging of fresh leaves, as shown in Figure 4c.

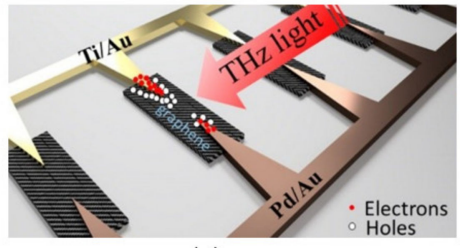

(a)

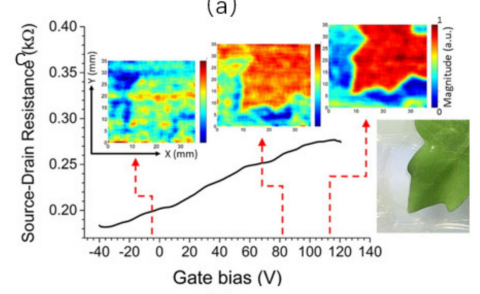

(c)

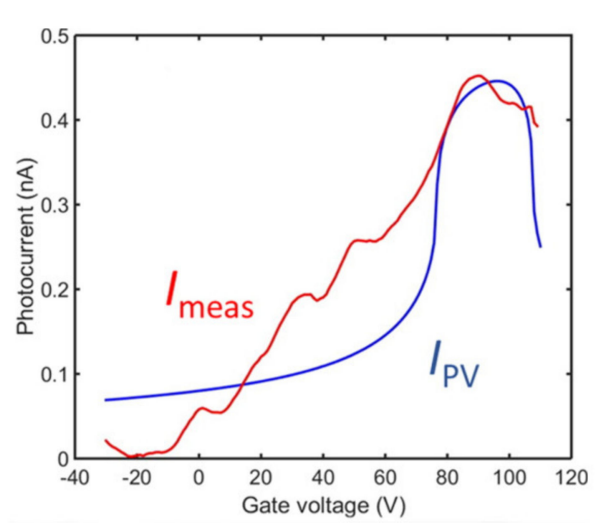

(b)

Figure 4. (a) Illustration of the photovoltaic-based detector concept map. (b) Blue trace $\mathrm{I}_{\mathrm{PV}}$ is the calculated photovoltaic current, and red trace $\mathrm{I}_{\text {meas }}$ is the measured photocurrent. (c) $\mathrm{The} \mathrm{THz}$ diagrams of fresh blades under different grid bias voltages. The three photos correspond to the bias voltages of 0,80 , and $110 \mathrm{~V}$ respectively. Reprinted with permission from ref. [73]. Copyright 2016 American Chemical Society. 
Temperature-dependent resistance in bilayer graphene is important in graphene detectors that use the photothermoelectric effect and must work at low temperatures [57,65]. Cai et al. [74] reported a $\mathrm{THz}$ detector based on the photothermoelectric effect. More interestingly, they generated an asymmetry by contacting graphene with dissimilar metals using a standard double-angle evaporation technique, as shown in Figure 5a. The electrons in graphene are heated by absorbing the energy of the $\mathrm{THz}$ wave. They found that the Fermi energy profiles are changed in the different devices due to their different metal contacts, and the heat dissipation of the contacts makes the temperature distribution of the device different, as shown in Figure 5c,d. By using the absorbed power instead of the incident power to define the response, the measurement allows for a better comparison of responses at different wavelengths. Interestingly, the sensitivity of detector is better than $10 \mathrm{~V} / \mathrm{W}$ without a coupling antenna, indicating that the performance of the $\mathrm{THz}$ detector has great potential for improvement.

a

(2)
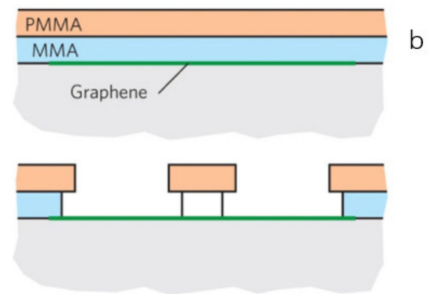

(3)

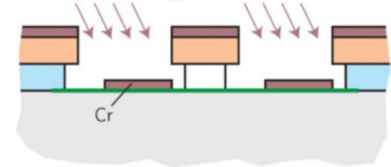

(4)

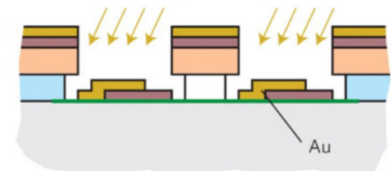

(5)

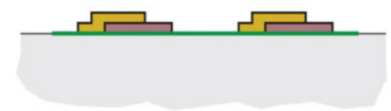

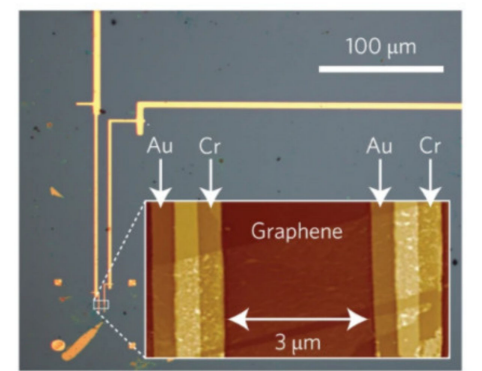

C

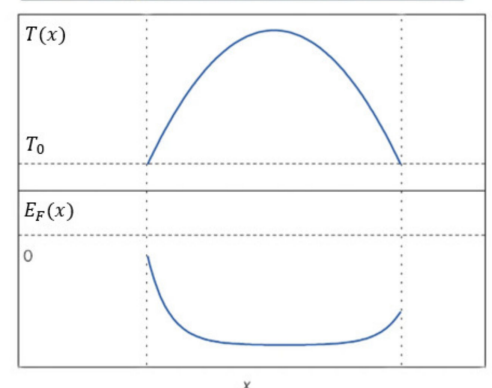

Figure 5. (a) Schematic illustration of the manufacturing mechanism of the detector with double angle evaporation technology. (1) MMA/PMMA is spun onto graphene. (2) Resist is patterned by an electron beam and developed. Successive angled evaporations of chromium (3) and gold (4) followed by liftoff produces a single-layer graphene device with dissimilar metal contacts on the opposing sides as shown schematically in (5). (b) The image of the electrical connection point of the detector in an optical microscope. (c,d) The curve of temperature $(\mathrm{T}(\mathrm{x}))$ and Fermi level $\left(\mathrm{E}_{\mathrm{F}}(\mathrm{x})\right)$ at different positions in graphene. Reprinted with permission from ref. [74]. Copyright 2021 Copyright Clearance Center.

The structure of the coupling antenna for the PTE THz detector can also considerably improve the detector's performance. Guo et al. [75] used ultraviolet lithography to prepare a square metal spiral antenna. This structure of antenna can increase the absorption area, approximately stabilize radiation impedance in the $\mathrm{THz}$ band, and be widely used in broadband detection [76]. For $\mathrm{THz}$ wave coupling and metallic electrodes, the antenna can be employed. Graphene is laid on the right side and connected to the metal in three places, which can ensure asymmetry without using different metal contacts. The maximum response of the detector is $28 \mathrm{~V} / \mathrm{W}$, and the response time is $9 \mu \mathrm{s}$. Compared with the detectors without an antenna [74], the detector coupled with the antenna has better performance in response and NEP. The electron heat capacity of graphene is low; thus, the temperature fluctuates dramatically under the same absorption energy, resulting in a higher photocurrent generated by the detector and increased sensitivity. For graphene, the carriers are heated by electron-electron interaction, which is faster than the electron- 
phonon method. Moreover, the heat balance maintains for a long time in graphene; as a result, the response speed of the graphene detector is fastened.

Another significant parameter to improve the characteristic of the $\mathrm{THz}$ detector is reducing the device resistance [77]. In 2019, Castilla et al. presented a sort of THz detector [78] that is connected with a two-branched antenna with a gap of roughly $100 \mathrm{~nm}$ between the antennas, as illustrated in Figure 6a. By applying an appropriate voltage on both the branches of the antenna, a $\mathrm{p}-\mathrm{n}$ junction in the graphene channel is created through the capacitive coupling, which had a small antenna gap and makes the carriers have a higher temperature under enhanced radiation intensity. The $\mathrm{THz}$ radiation is concentrated and enhanced in this p-n junction, resulting in a photocurrent response. There is no electrical connection between the detector antenna and the graphene. Meanwhile, the resistance of the entire device is reduced, and the performance of the detector is remarkably enhanced. By measuring the photocurrent as a function of the bias voltage applied between the source and drain contacts, it is found that the PTE is the main mechanism that dominates the photon response of the detector. In addition, the incident wave frequency is changed from 1.83 to $4.25 \mathrm{THz}$, and the response center is observed at about $3 \mathrm{THz}$. However, the response center is at $2 \mathrm{THz}$ in the full-wave simulation, as shown in Figure 6b. This discrepancy can be attributable to the antenna's limitations. Using an antenna with a wider spectral range will expand the detection range of the detector.
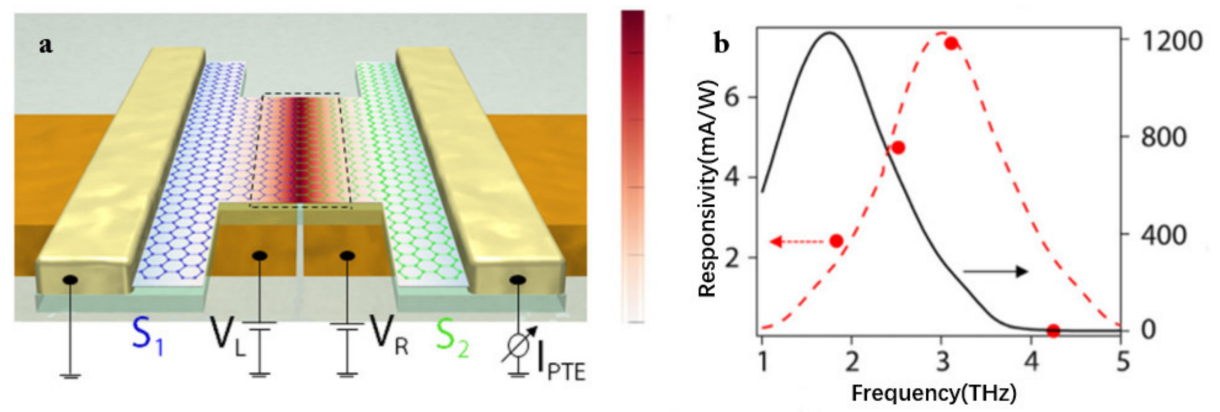

Figure 6. (a) The schematic illustration of the fabricated device. Appropriate voltage is applied to both sides of the antenna, and the terahertz radiation will be concentrated in the central part of the graphene channel (where incident terahertz wave is concentrated by the antenna). (b) The black line is the simulation result, and the red line is the trend of the experimental results. Reprinted with permission from ref. [72]. Copyright 2019 American Chemical Society.

In addition, there are many studies on the performance of $\mathrm{THz}$ detectors. Metamaterials are an effective way to enhance the performance of graphene photodetectors [78,79]. The absorption of $\mathrm{THz}$ can be greatly enhanced by a periodically tunable plasma perfect metamaterial absorber with a square-square-circle graphene array [80]. A large area and rapid $\mathrm{THz}$ detector was accomplished by transferring graphene on a patterned silicon substrate to establish a Schottky junction [81]. Using three-dimensional graphene foam could also make ultra-wideband and high-sensitivity $\mathrm{THz}$ detectors [82]. Other researchers have studied the physical properties of graphene carrier transport and terahertz-thermoelectric conversion under different annealing treatments [83].

\subsubsection{The Photodetector Based on Plasma Wave Resonance}

In 1993, Dyakonov and Shur proved that the electron behavior in a short channel field effect transistor (FET) is similar to that in shallow water, which provides a new mechanism to detect $\mathrm{THz}[84,85]$. The plasmonic wave is the basic mechanism of the graphene field effect transistor (GFET) utilized as a THz detector. When there is a high concentration of electrons in the channel of the FET, the electrons will collide during the transmission and do not follow the ballistic transmission mechanism. In this case, the electrons can be regarded as two-dimensional electron gas $[84,86,87]$. When the $\mathrm{THz}$ wave is irradiated on the detector, it will excite the plasmonic wave. The channel of the device can just become 
the resonant cavity of the plasmonic wave. With the resonance, a voltage or current will be generated between the source and the drain. The magnitude of the generated current or voltage is related to the power of the incident wave $[68,88]$. In FET, the frequencies of the eigen plasmon modes are

$$
\begin{gathered}
\omega_{\mathrm{N}}=(2 \mathrm{~N}-1) \omega_{0} \\
\omega_{0}=\frac{\pi}{2 \mathrm{~L}} \sqrt{\frac{\mathrm{e}\left(\mathrm{U}_{\mathrm{g}}-\mathrm{U}_{\mathrm{th}}\right)}{\mathrm{m}^{*}}}
\end{gathered}
$$

where $\mathrm{L}$ is the gate length, $\mathrm{U}_{\mathrm{g}}$ is the gate voltage, $\mathrm{U}_{\mathrm{th}}$ is the threshold voltage, and e and $\mathrm{m}^{*}$ are the electron charge and effective mass, respectively. The resonance mode can be adjusted by adjusting the size of the channel or the electron density [89], the concentration of carriers in graphene could be tuned by doping. When the carrier concentration is moderate, the plasmonic oscillation frequency in graphene is in the $\mathrm{THz}$ band [90,91]. A broadband $\mathrm{THz}$ detector can be made by modulating the Fermi energy level and changing the structure size [92]. The electrons in graphene are massless Dirac fermions [93], so the coupling of electromagnetic waves and plasmonic waves in graphene is stronger than other materials.

In 2007, Echtermeyer et al. [94] reported for the first time an FET made by graphene and suggested that graphene FET had great potential. In 2008, Ryzhii et al. developed a graphene bilayer phototransistor model and calculated its current-voltage characteristics at sufficiently large gate voltages [95]. After that, Lin et al. produced graphene-based transistors with a cutoff frequency of $100 \mathrm{GHz}$ [96] and graphene-based integrated circuits (IC) [97], as shown in Figure 7. Hence, the application of the graphene field-effect transistors in the field of $\mathrm{THz}$ detectors has been intensively developed [71].

a
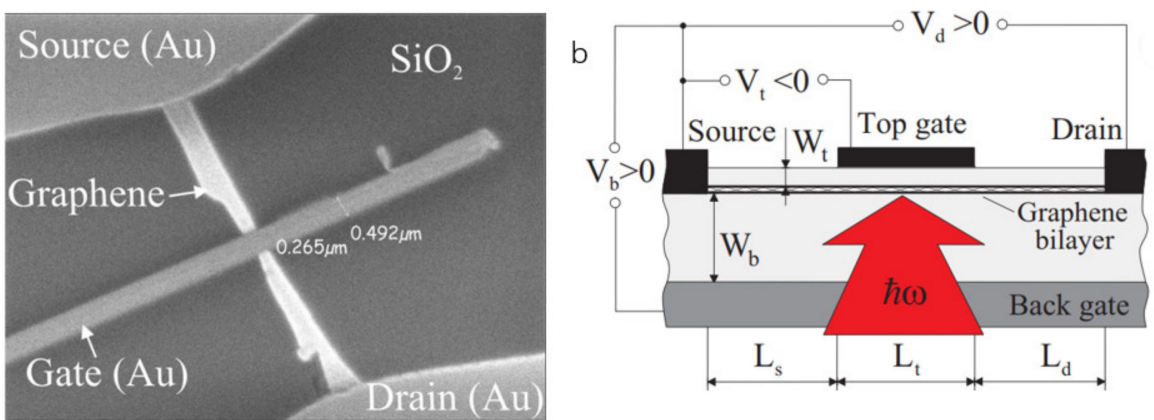

C
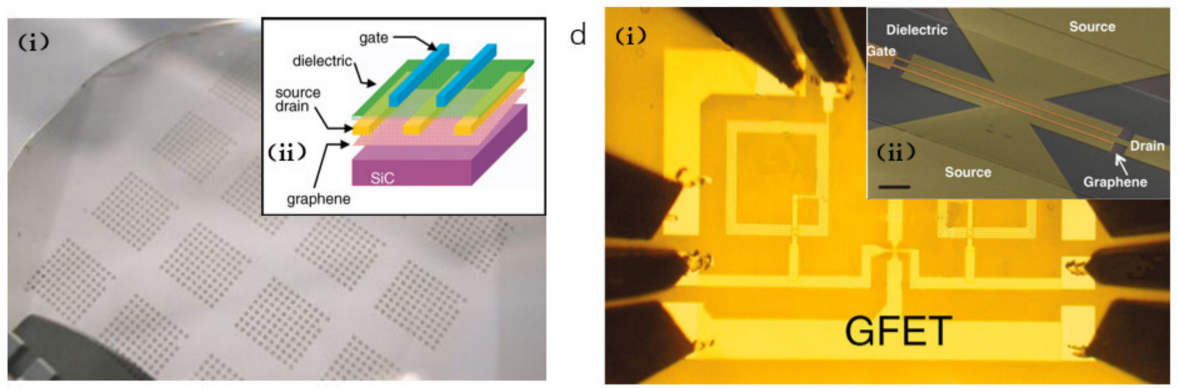

Figure 7. (a) The SEM image of a graphene device. Reprinted with permission from ref. [94]. Copyright 2021 Copyright Clearance Center. (b) Schematic view of a graphene terahertz radiation detector. Reprinted with permission from ref. [95]. Copyright 2021 American Physical Society. (c) (i) Image of devices fabricated on a 2-inch graphene wafer, (ii) the schematic cross-sectional view of a top-gated graphene FET. Reprinted with permission from ref. [96]. Copyright 2021 Copyright Clearance Center. (d) (i) Scanning electron image of a top-gated, dual-channel graphene transistor used in the mixer IC. (ii) Optical image of a completed graphene mixer. Reprinted with permission from ref. [97]. Copyright 2021 Copyright Clearance Center. 
The working frequency of the $\mathrm{THz}$ detector is related to the size of the device. Therefore, to detect the higher frequency $\mathrm{THz}$ waves, large size graphene is needed $[98,99]$. Tong et al. [100] used a method that coupled small-size graphene coupled with a rectangular antenna to achieve 1-3 THz detection. In order to better adapt to the $2 \mathrm{THz}$ frequency, two rectangular metal antennas are used in the article sandwich graphene to act as the source and drain of the transistor. This FET had the function of emitting and detecting $\mathrm{THz}$ waves. The maximum $\mathrm{THz}$ wave output power is $2.1 \mathrm{nW}$ in the range of $1-3 \mathrm{THz}$. The external radiation is coupled to the antenna through the enhancement of the silicon lens, and the performance of the detector is significantly improved. The maximum response rate is $4.9 \mathrm{~V} / \mathrm{W}$ at room temperature, and the NEP is $1.7 \mathrm{nW} / \mathrm{Hz}^{1 / 2}$.

Qin et al. [101] reported a GFET based on a self-mixing mechanism. The source and drain contacts to the bilayer graphene channel are two dipole antennas, as shown in Figure 8a, and the field-effect gate is located in the gap between the source and drain antennas. The THz electromagnetic wave is fed to the grid through the gate antenna, and a strong local terahertz field is induced in the graphene channel near the grid channel of the gate facing the drain antenna. The NEP of direct detection of $216 \mathrm{GHz}$ and $648 \mathrm{GHz}$ is $8 \mathrm{nW} / \mathrm{Hz}^{1 / 2}$ and $1 \mathrm{nW} / \mathrm{Hz}^{1 / 2}$, respectively. The local oscillator of $2 \mathrm{nd}$ harmonic $(432 \mathrm{GHz})$ and 3rd harmonic $(648 \mathrm{GHz})$ mixing detection of $216 \mathrm{GHz}$, and its NEP is $3 \mathrm{nW} / \mathrm{Hz}^{1 / 2}$ and $1 \mathrm{nW} / \mathrm{Hz}^{1 / 2}$, respectively, mixing loss is $38.4 \mathrm{~dB}$ and $57.9 \mathrm{~dB}$, respectively. They scanned fresh leaves at different frequencies, and the results are shown in Figure 8b. Through selfmixing detection at $216 \mathrm{GHz}, 432 \mathrm{GHz}$, and $650 \mathrm{GHz}$ happened, the response characteristics of the detector are proved to meet with the design.
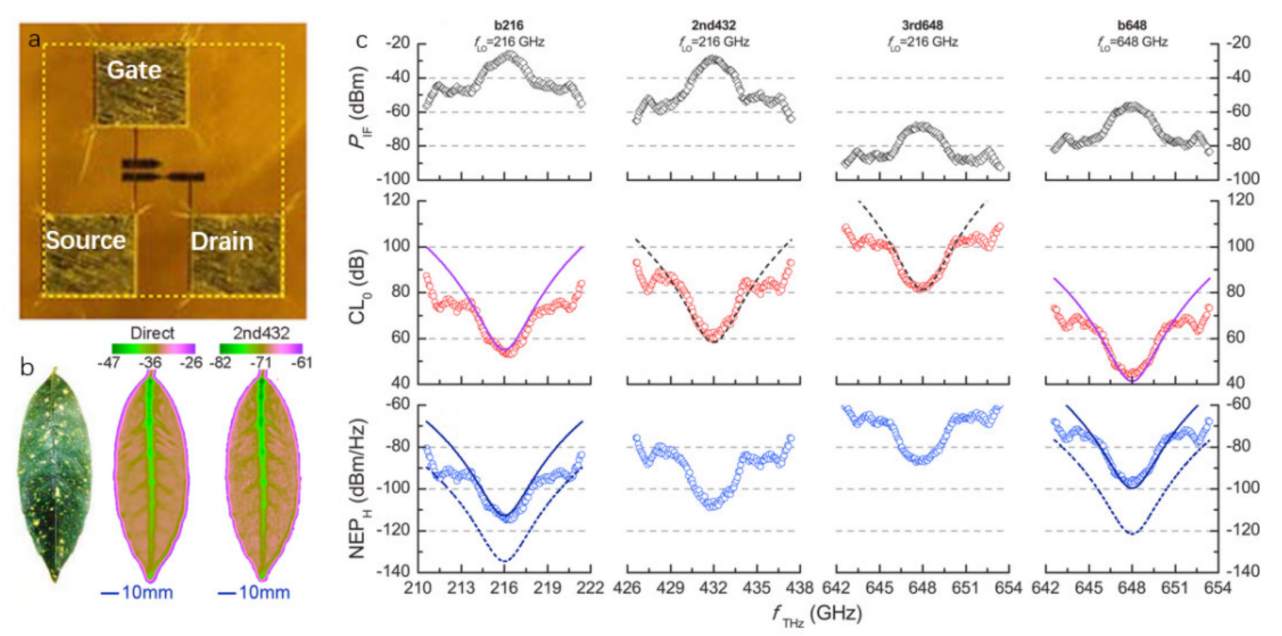

Figure 8. (a) The optical microscope image of the detector. (b) The photographs of the direct detection and second harmonic detection of fresh blades at $432 \mathrm{GHz}$, respectively. (c) The experimental results at different frequencies. The top, middle, and bottom represent the incident power, mixing loss, and noise power, respectively. Reprinted with permission from ref. [101]. Copyright 2021 Copyright Clearance Center.

Mittendorff et al. [102] investigated the effect of the substrate on the detector's performance. They used the undoped silicon substrates and heavy P doped silicon substrate coupled with metal antennas to fabricate the $\mathrm{THz}$ detectors. The beam is focused on the devices by off-axis parabolic mirrors, using the lock-in amplifier to measure the timeintegrated photocurrent. The results illustrate that the signal rise time of the doped silicon substrate detector is about $50 \mathrm{ps}$, while the rise time of the undoped detector is within $100 \mathrm{ps}$, and the signal amplitude has also decreased. The antenna forms a capacitor on the substrate, and the substrate acts as a dielectric material, so its resistivity affects the $\mathrm{RC}$ time constant. In order to prove that the photocurrent generated by the detector is graphene instead of the antenna, they removed the graphene sheet on the detector and did not detect any signal under $\mathrm{THz}$ irradiation. The signal generated by the detector can be 
attributed to graphene. Under a particular wavelength range (below $20 \mu \mathrm{m}$ ), the phonons in Si absorb thermally active carriers, causing the device to heat up and the substrate resistance to decrease. Therefore, the choice of substrates using different materials (such as $\mathrm{SiC}$ or diamond) or different doping of silicon is also an important direction for research and improvement of graphene $\mathrm{THz}$ detectors.

The plasmonic wave detection requires the asymmetrical coupling of source and drain. The non-linear rectification of the carrier transmission is a direct detection, and the detection by the PTE is realized by asymmetric contact [100]. Liu et al. [103] introduced a symmetrical pair of fingers in a graphene detector based on antenna coupling, as shown in Figure 9a. There are four terminals in the detector, which can switch the light detection mode by controlling different contact configurations in the graphene channel. The function of the photocurrent can be calculated by comparing the shape of the photocurrent curve. More interestingly, the decreasing in the length of the channel or increasing the dipole interaction between the two opposite antenna arms can efficiently enhance the performance of the detector. However, by the bias field effect, the maximum voltage response of the device reaches $280 \mathrm{~V} / \mathrm{W}$. The performance of the detector is different under different working modes. As shown in Figure $9 \mathrm{~b}$, the NEP of the device in photovoltaic mode is $100 \mathrm{pW} / \mathrm{Hz}^{1 / 2}$, and the responsivity is $100 \mathrm{~V} / \mathrm{W}$. When the device works in light guide mode, the performance of the device is reduced, as shown in Figure $9 \mathrm{~b}$. The NEP is about $500 \mathrm{pW} / \mathrm{Hz}^{1 / 2}$, and the responsivity is about $10 \mathrm{~V} / \mathrm{W}$. There is a mismatch between the result and the theoretical result, which may be due to the super-large antenna used and the long channel have a remarkable effect on detector efficiency. It is possible that optimizing the antenna would further enhance the performance of the $\mathrm{THz}$ detector.
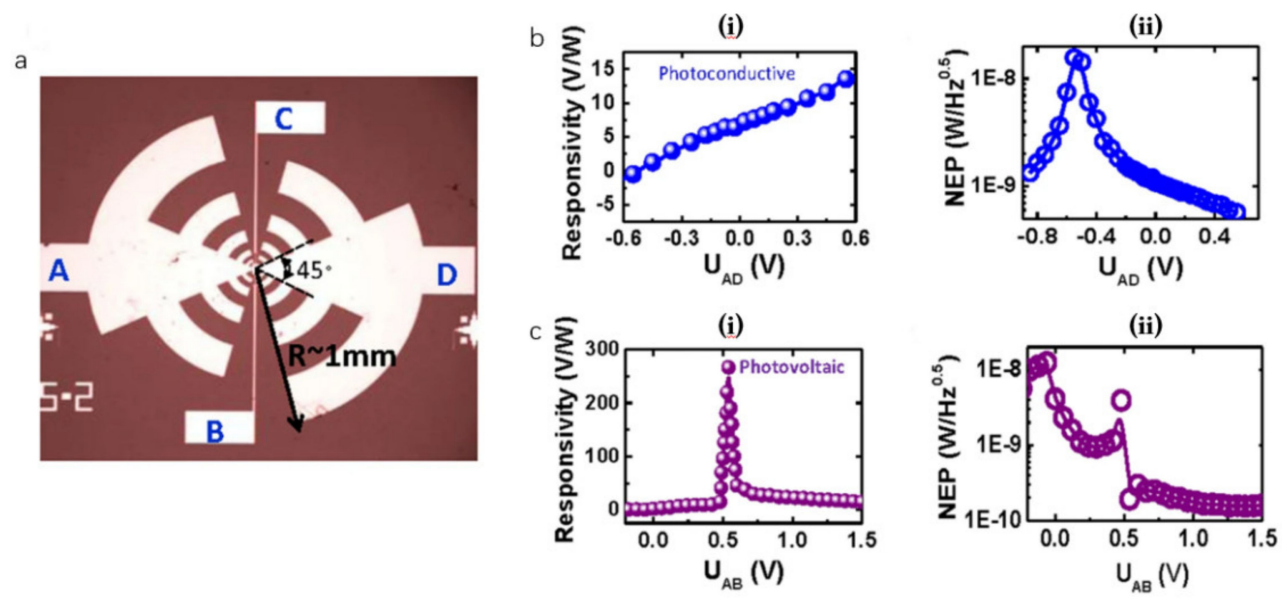

Figure 9. (a) The electrical configuration of the device, and changing the connections of the four terminals switch modes, (b) The responsivity and NEP curve in photoconductive mode. (c) The responsivity and NEP curve in photovoltaic mode. Reprinted with permission from ref. [103]. Copyright 2018 The Author.

The structure parameters of the antenna also played an important role in the performance of the FET. In 2020, Viti et al. [104] encapsulated single-layer graphene (SLG) in the hexagonal boron nitride (hBN) to form a clean hBN-SLG-hBN heterostructure, which was coupled with butterfly antennas to make graphene FET. When the antenna parameters were chosen, they referred to the results of electromagnetic simulation. The radius of the antenna increased from 6 to $69 \mu \mathrm{m}$. At $20 \mu \mathrm{m}$, the in-plane component of the electric field showed a $\lambda / 2$ resonance, and at $52 \mu \mathrm{m}$, a $3 \lambda / 2$ resonance appeared. The detector uses the synchronization mechanism of photovoltaic effect and PTE to achieve low noise $\left(\mathrm{NEP}=160 \mathrm{pW} / \mathrm{Hz}^{1 / 2}\right)$ room temperature $\mathrm{THz}$ detector. The responsivity is $49 \mathrm{~V} / \mathrm{W}$ when exposed to $3 \mathrm{THz}$ radiation at room temperature and $180 \mathrm{~V} / \mathrm{W}$ at a low temperature $(77 \mathrm{~K})$. It can be found that changing the size of the antenna will tune its resonant frequency, and changing the antenna type can also reduce or expand its frequency coverage. 
In order to increase the absorption of graphene, many effective ways such as quantum dot enhancement, antenna coupling enhancement, and plasmonic enhancement can be used [105-107]. Direct contact between the edge of the graphene micro-strip and the metal electrode will hinder the excitation of plasmon resonance. Mohammad et al. [108] reported on a plasmonic-enhanced $\mathrm{THz}$ detector. In this detector, graphene micro-strips are designed with a specific angle to make the electrode array, in which the plasmon mode is associated with currents transverse to the ribbon and can be efficiently excited by light and polarized perpendicular to the metal electrodes. They study the absorption of $\mathrm{THz}$ waves with different structures, including graphene micro-strips without metal electrodes, graphene micro-strips with vertical metal electrode arrays, and graphene micro-strips with inclined metal electrodes. The findings show that direct contact between the edge of the graphene micro-strip and the metal electrode prevents plasmon resonance excitation [109], and the plasmon resonance enhancement of the vertical structure is smaller than that of the graphene micro-strip without metal electrodes. Meanwhile, the enhancement in the case of the inclined structure is larger than the vertical structure enhancement. Subsequently, they shortened the distance between the electrodes to $3.8 \mu \mathrm{m}$, which is closer to the diffusion length of graphene hot carriers. In the same area, the short-distance structure can integrate more arrays, which would further enhance the photoelectric signal.

The interference of plasma oscillations in the channel of the field-effect transistors can be used to measure radiation polarization [110]. Sergey et al. [111] fabricated a plasmonic interferometer based on GFET. After absorbing radiation, the source and drain of the GFET excite plasma waves and interfere inside the channel. The antenna sleeves are attached to the electrodes, and the drain sleeves are bent 45 degrees to guarantee that the radiation is asymmetrically coupled to the source and drain. The amplitudes and phases of the source and drain are different, realizing a spiral-sensitive $\mathrm{THz}$ plasma interferometer. Changing the angle between the laser polarization and the main axes of the $\lambda / 4$ could control the helicity of the radiation. They measured the helicity dependence of the photovoltage normalized by the radiation power $\mathrm{P}$. The results show that when the phase of the device is asymmetrical, the helicity-sensitive response occurs, and when the signal amplitude is asymmetrical, the helicity-insensitive response arises. This work provides a basis for the phase-sensitive detection of plasma waves excited by two-dimensional materials.

The antenna will be coupled with the rectifying device by GFET, but the detector performance was affected by the rectifying of the parasitic capacitance. Gregory et al. [112] fabricated an asymmetric four-terminal ballistic rectifier structure, which relies on the ballistic motion of the carrier to rectify alternating current signals into direct current output. In the ballistic state of electron transmission, the carriers will not be randomly scattered by phonons or impurities. Electrons will be hit in a specific direction at the edge of the device to achieve a rectification effect. In this rectification method, the carriers do not need to overcome the built-in electric field, and the device threshold voltage is 0 , which reduces the introduction of parasitic capacitance. They fabricated the device using graphene made by mechanical exfoliation. The responsivity is $764 \mathrm{~V} / \mathrm{W}$ under $0.45 \mathrm{THz}$ radiation, and the NEP is as low as $34 \mathrm{pW} / \mathrm{Hz}^{1 / 2}$. Finally, they also achieved imaging of opaque objects under $0.685 \mathrm{THz}$ radiation.

The responsivity of the traditional FET is affected by the channel conductivity, and the transconductance is limited by $\rceil / \mathrm{k}_{\mathrm{B}} \mathrm{T}$. This limitation has little effect on the responsivity of the detector and is easily overlooked. Bandurin et al. [67] developed a tunnel fieldeffect transistor (TFET) model to rectify high-frequency signals. Since the thermoelectric plays a minor part in this scenario, the responsivity of the detector is governed by the responsivity of the channel and the tunnel junction. The tunnel barrier is essentially non-existent under normal conditions, and the responsivity is dictated by the channel responsivity. When a vertical electric field is applied to the graphene channel, a tunnel junction is formed, and the tunnel conductance is very sensitive to the junction voltage. This greatly improves the sensitivity of the TFET. In order to verify this model, a dual-gated bilayer graphene $\mathrm{THz}$ detector was fabricated. The responsivity of tunnel detection under 
$0.13 \mathrm{THz}$ radiation reaches $3000 \mathrm{~V} / \mathrm{W}$, which is an order of magnitude higher than that without tunnel detection, and the NEP is about $0.2 \mathrm{pW} / \mathrm{Hz}^{1 / 2}$. In theory, the response of this detection method can reach $100 \mathrm{kV} / \mathrm{W}$, and after achieving the antenna and TFET impedance matching, the NEP can have a significant reduction.

\section{Terahertz Detectors Made by Different Graphene Preparation Methods}

The development of ways to manufacture graphene increases graphene application, which is an exciting occurrence. The reason is that the methods of making graphene are different, and their properties determine the application. In addition to the mechanical exfoliation method where graphene was first discovered, there are liquid exfoliation methods, molecular beam epitaxy [113], chemical vapor deposition (CVD), SiC epitaxial growth, etc. Liquid exfoliation is that exposing the graphite to organic solvents such as N-methylpyrrolidone. The surface tension of the solvent will cause the graphite to crack [114]. This method can make graphene on a mass scale, but the carrier mobility is small, which is suitable for transparent conductive materials or coatings [115]. Since the photon energy is only a few $\mathrm{meV}$ in the $\mathrm{THz}$ range, graphene used in $\mathrm{THz}$ detectors requires high electron mobility. The sensitivity of graphene $\mathrm{THz}$ detectors can reach the order of $\mathrm{pW} / \mathrm{Hz}^{1 / 2}$, and the response speed can reach the order of ps, but the performance of the current graphene detectors is far below the ideal value [116]. The graphene preparation methods currently used for the $\mathrm{THz}$ detectors mainly depend on mechanical exfoliation, CVD, SiC epitaxial growth, etc. [117].

\subsection{Mechanical Exfoliation}

Geim and Novoselov reported mechanical exfoliation for the first time in 2004 [40]. More specifically, the graphite is separated into smaller pieces, and the thinner pieces of graphite are selected. They used a specific method to divide the graphite sheet into two halves and repeated this process continuously to get thinner and thinner graphite sheets. A small number of samples are graphene composed of a single layer of carbon atoms [118-120]. This method of graphene manufacturing does not degrade the intrinsic characteristics of graphene, making it ideal for high-frequency electrical and optical devices.

The graphene-dielectric integration process will introduce substantial defects into pristine graphene lattices, which reduce the mobility in graphene. In addition, an immature manufacturing process leads to large access resistance. These two points lead to the poor performance of graphene $\mathrm{THz}$ detectors compared to other mature FET detectors [121-123]. Liao reported a new way to make GFET by using $\mathrm{Co}_{2} \mathrm{Si}-\mathrm{Al}_{2} \mathrm{O}_{3}$ core-shell nanowires as a self-aligned top gate to fabricate graphene transistors [124]. The graphene made by mechanical exfoliation is transferred to the silicon substrate, and the $\mathrm{Co}_{2} \mathrm{Si}_{-}-\mathrm{Al}_{2} \mathrm{O}_{3}$ core-shell nanowires are aligned with the graphene by the physical dry transfer method. Finally, a layer of metal is deposited on the structure. Hence, the nanowire acts as a mask, forming a self-aligned source and drain electrodes on both sides. The graphene transistor produced by this method has lower access resistance and less impurities introduced in the manufacturing process; the carrier mobility can reach $20,000 \mathrm{~cm}^{2} / \mathrm{V} \cdot \mathrm{s}$, and the cutoff frequency is 100-300 GHz.

Vicarelli et al. [122] used single-layer and bilayer graphene prepared by mechanical exfoliation to fabricate an antenna-coupled graphene FET. The coupled antenna is a logperiodic antenna, as shown in Figure 10a, and the channel length is demonstrated in Figure $10 \mathrm{~b}$, which is a low parallel capacitance antenna that leads to ensure the selectivity of the spatial mode and the polarization of the incident radiation. Furthermore, the antenna can also ensure the asymmetry of the source and drain. The plasma wave excited in the channel of the FET realizes the detection of $0.3 \mathrm{THz}$ at room temperature. As shown in Figure 10b,c, the NEP and responsivity of the single-layer graphene detector are $200 \mathrm{nW} / \mathrm{Hz}^{1 / 2}$ and $0.1 \mathrm{~V} / \mathrm{W}$, and the NEP and responsivity of the bilayer graphene detector are $30 \mathrm{nW} / \mathrm{Hz}^{1 / 2}$ and $0.15 \mathrm{~V} / \mathrm{W}$, respectively. 

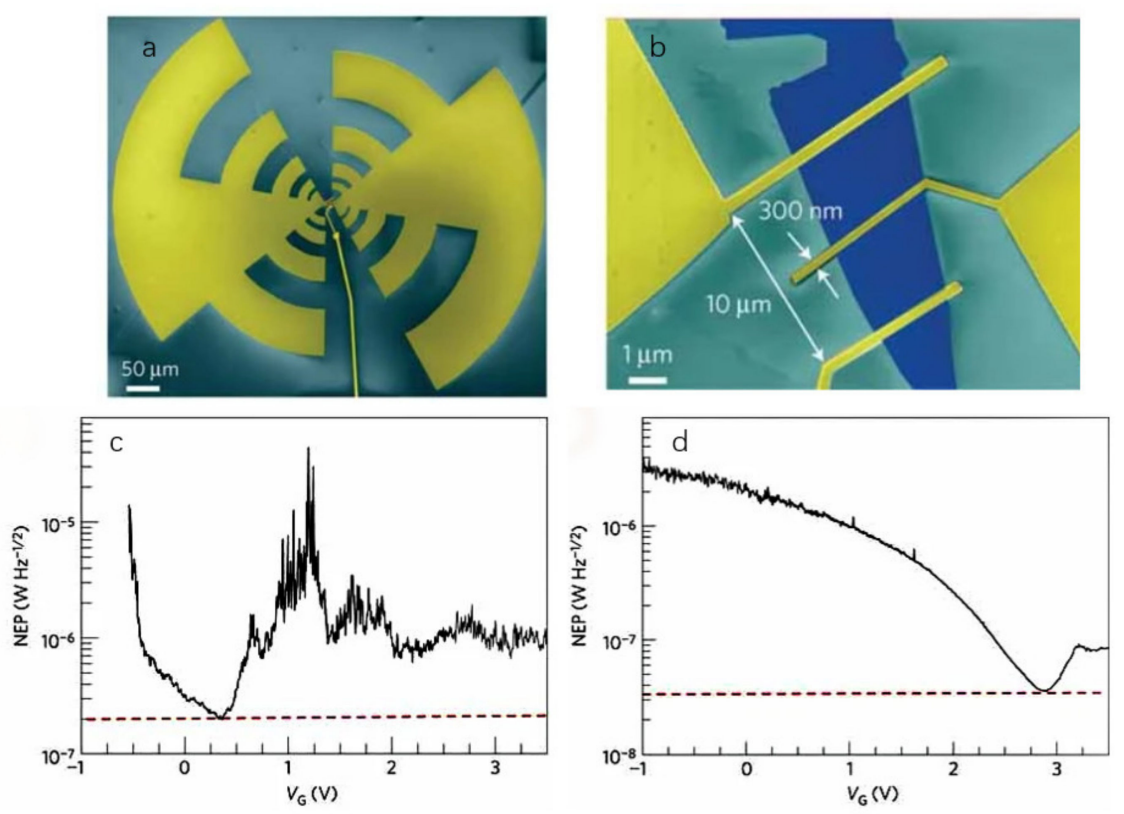

Figure 10. (a) The model of the fabricated detector. (b) The channel length is $10 \mu \mathrm{m}$, with a gate width $300 \mathrm{~nm}$. (c) The curve of NEP with single-layer graphene, and (d) The bilayer graphene in which the dotted line indicates the minimum value. Reprinted with permission from ref. [122]. Copyright 2021 Copyright Clearance Center.

Packaging graphene with standard dry skin technology can provide the cleanest environment for graphene [125]. Bandurin et al. [126] using graphene made by mechanical exfoliation and encapsulated by hBN. The carrier mobility is as high as $30,000 \mathrm{~cm}^{2} / \mathrm{V} \cdot \mathrm{s}$ at room temperature. They fabricated several devices of different sizes and used the gate to tune plasmon speed to conduct experiments in multiple resonance modes. FET devices with a feature size of $4 \mu \mathrm{m}$ have observed plasmon resonance in the frequency range of $0.13-2 \mathrm{THz}$. At $0.13 \mathrm{THz}$, the NEP is as low as $10^{-13} \mathrm{~W} / \mathrm{Hz}^{1 / 2}$, and the responsivity is $3000 \mathrm{~V} / \mathrm{W}(10 \mathrm{~K})$. The performance is comparable to bolometers (commercial devices) operating at low temperatures (below $5 \mathrm{~K}$ ). It indicates that a high-mobility graphene FET that uses far-field coupling to incident radiation can be used as a resonant $\mathrm{THz}$ photodetector, and it demonstrates the remarkable advantages of graphene materials with high mobility in $\mathrm{THz}$ detection.

\subsection{Chemical Vapor Deposition}

Under high temperatures and certain conditions, carbon atoms are deposited on the metal surface using a mixture of methane and hydrogen or other carbon sources to form large-area graphene film $[127,128]$. Chemical vapor deposition mainly includes thermal CVD, plasma-enhanced CVD, and hot filament CVD [129-131]. These methods can control the growth thickness and size of graphene. At the same time, it can achieve uniform doping of graphene by introducing heterogeneous materials such as nitrogen and carbon, which is beneficial to the functionalization or fine-tuning of the graphene transistors [132]. The carrier mobility of the graphene prepared by the CVD method can reach $40,000 \mathrm{~cm}^{2} / \mathrm{V} \cdot \mathrm{s}$ at $300 \mathrm{~K}$ and $180,000 \mathrm{~cm}^{2} / \mathrm{V} \cdot \mathrm{s}$ at $2 \mathrm{~K}$ [133]. This CVD-grown graphene has low cost and high quality, which makes it one of the most widely used methods.

Zak et al. explored the use of CVD-grown graphene for the detection of $\mathrm{THz}$ signals [134]. They transfered the graphene grown on copper foil to the substrate using a frame-assisted bubbling transfer process. The mobility of electrons and holes in the fabricated device is $1800 \mathrm{~cm}^{2} / \mathrm{V} \cdot \mathrm{s}$ and $1200 \mathrm{~cm}^{2} / \mathrm{V} \cdot \mathrm{s}$, respectively. This detector is coupled with a slit-structured butterfly antenna. The resistance is calculated by the ratio of $\Delta \mathrm{U}$ and $\Delta \mathrm{I}$ of the rectified voltage, and the current response is measured under $\mathrm{THz}$ self-mixing. This 
calculation result is consistent with the direct current and voltage measurement calculation results, ensuring that the measurement result is perfect and reliable. The device can detect $\mathrm{THz}$ signals at $0.6 \mathrm{THz}$ at room temperature, and the measured maximum responsivity and minimum NEP are $14 \mathrm{~V} / \mathrm{W}$ and $515 \mathrm{pW} / \mathrm{Hz}^{1 / 2}$, respectively. This work proves that CVD graphene-based $\mathrm{THz}$ detectors have great potential.

However, the fabrication process of the device will introduce impurities in the graphene, which will affect the performance of the detector. In order to solve this problem, Generalov et al. [135] used CVD-grown graphene to design and fabricate a special room-temperature graphene-based $\mathrm{THz}$ detector with a working frequency of $400 \mathrm{GHz}$. The detector has a slit butterfly-shaped asymmetric antenna structure with a radius of $160 \mu \mathrm{m}$, as shown in Figure 11a,b. They improved the device manufacturing process on Zak's work [134]. We used the pre-growing dielectric gate method to deposit a layer of dielectric $\mathrm{Al}_{2} \mathrm{O}_{3}$ gate and then make the source and drain, as shown in Figure 11c, which ensures that other substances do not touch the graphene in the FET channel in the subsequent measures. The signal from the antenna is fed to the gate-source terminal. The gate-drain terminal has capacitive coupling, which is achieved by separating the bow-tie antenna. The electron and hole mobility of the device made by this method are $3100 \mathrm{~cm}^{2} / \mathrm{V} \cdot \mathrm{s}$ and $2800 \mathrm{~cm}^{2} / \mathrm{V} \cdot \mathrm{s}$, respectively. The maximum responsivity reaches $74 \mathrm{~V} / \mathrm{W}$, and the NEP reaches $130 \mathrm{pW} / \mathrm{Hz}^{1 / 2}$.

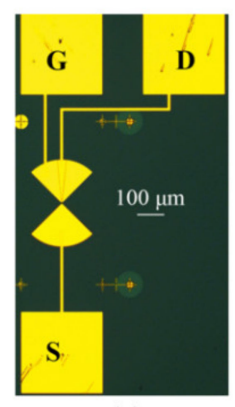

(a)

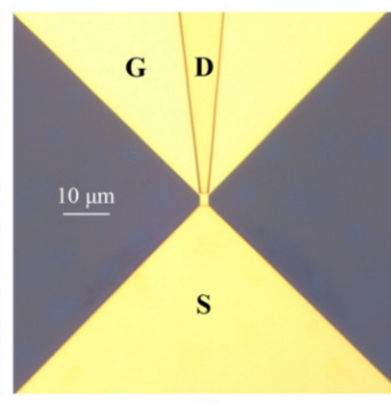

(b)

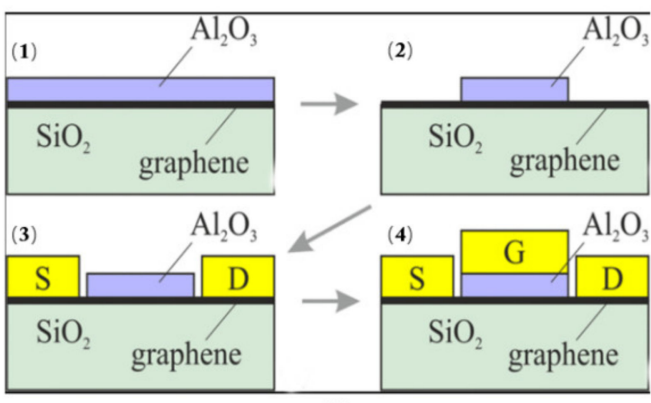

(c)

Figure 11. (a,b) The optical microscope image of the fabricated GFET detector (S, G, and D-source, gate, and drain, respectively) and the image of the GFET detector in the center of the antenna. (c) Schematic illustration of the fabrication steps of the graphene FET detector. (1) The graphene layer was covered by a thin $\mathrm{Al}$ seed layer and followed by natural oxidation; then, an $\mathrm{Al}_{2} \mathrm{O}_{3}$ gate dielectric was grown on top of the seed layer by atomic layer deposition. (2) The Al2O3 was patterned and etched with a buffered oxide etch. (3) The source and drain contacts were fabricated by evaporating. (4) The gate electrode was evaporated and patterned on top of the patterned $\mathrm{Al}_{2} \mathrm{O}_{3}$ layer. Reprinted with permission from ref. [135]. Copyright 2021 Copyright Clearance Center.

\subsection{SiC Epitaxial Growth}

A graphene layer can be formed on the silicon or carbon surface of the SiC wafer by sublimating the Si atoms on the surface of the SiC (0001) wafer and annealing the remaining $\mathrm{C}$ atoms to graphitize them $[136,137]$. Without the need for further transfer, this process can prepare large-scale and high-quality wafer-level graphene. Its electrical properties are similar to those of single-layer graphene produced by mechanical exfoliation, with mobility of up to $6600 \mathrm{~cm}^{2} / \mathrm{V} \cdot \mathrm{s}$ [138], which can be directly applied to the development of electronic devices.

An FET made of SiC epitaxial growth graphene was reported by Bianco [139]. The detector incorporates two mechanisms for the detection of THz. One is plasmonic detection due to the non-linearity of electron transport, and the other is the thermoelectric effect due to the presence of junctions of carrier density and induced temperature gradient through the FET. They investigate the contribution of the relevant processes using the particular dependency of positive gate voltages. The results suggest that plasmonic detection plays a vital role in the detection, but it is decreased by the thermoelectric impact. At the frequency 
of $295 \mathrm{GHz}$ and $353 \mathrm{GHz}$, the responsivity is $0.25 \mathrm{~V} / \mathrm{W}, 0.15 \mathrm{~V} / \mathrm{W}$, and NEP is $80 \mathrm{nW} / \mathrm{Hz}^{1 / 2}$, $160 \mathrm{nW} / \mathrm{Hz}^{1 / 2}$, respectively.

Qin et al. [140] fabricated an FET based on bilayer graphene. A 2-inch 4H-SiC (0001) graphene wafer was used as substrate-grown monolayer graphene at a high temperature of $1550{ }^{\circ} \mathrm{C}$ in an argon atmosphere. Then, they annealed the monolayer epitaxial graphene in molecular hydrogen at $900{ }^{\circ} \mathrm{C}$ to obtain the bilayer graphene. The structure of the detector is shown in Figure 12a,b. The detector has a voltage responsivity of $30 \mathrm{~V} / \mathrm{W}$ and a NEP of $51 \mathrm{pW} / \mathrm{Hz}^{1 / 2}$ at the $0.33 \mathrm{THz}$. Transmission-type THz imaging of a fresh leaf was studied by using the GFET detector with the gate floating as a proof-of-concept experiment on a two-terminal detector. As shown in Figure 12d, a GFET detector with a floating gate was used to study the transmission-type THz imaging of fresh leaves.
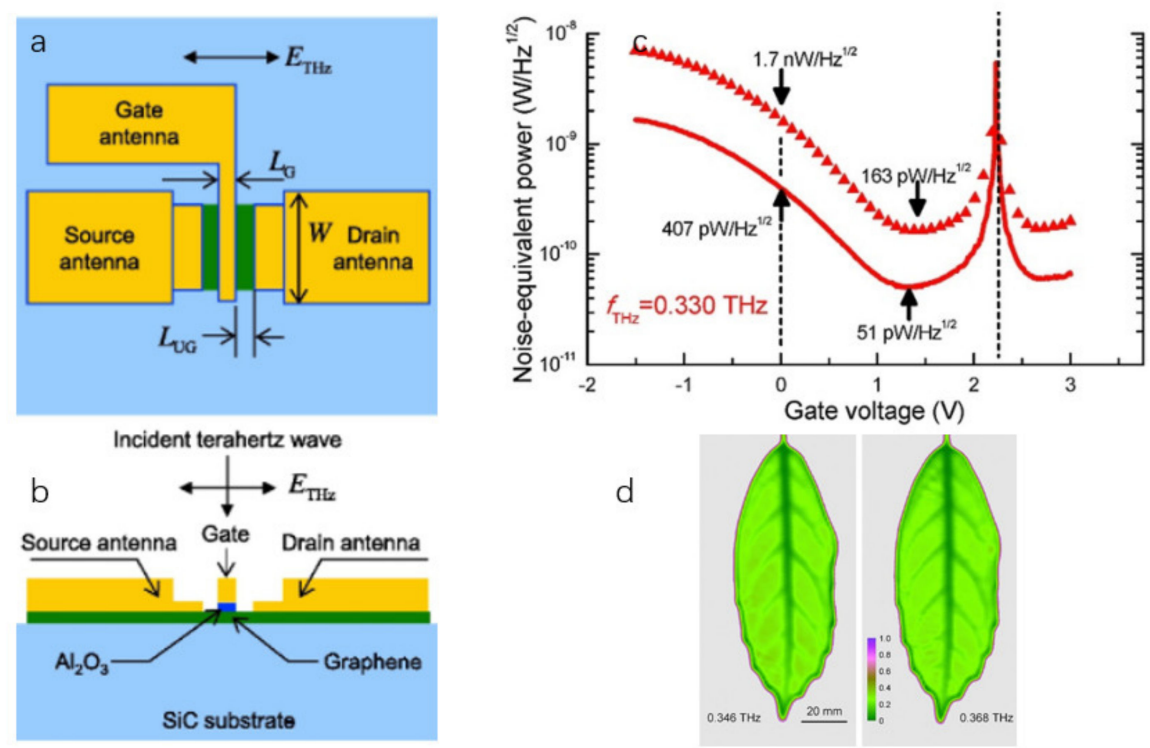

Figure 12. $(\mathbf{a}, \mathbf{b})$ The top view and front view illustration of the fabricated detector, respectively. (c) The red curve calculated from the responsivity at $0.330 \mathrm{THz}$ and the thermal noise of the detector, and the triangle line is calculated based on the responsivity and the noise spectral density dominated by the voltage pre-amplifier. (d) The photo of using this detector to image fresh leaves. Reprinted with permission from ref. [140]. Copyright 2021 Copyright Clearance Center.

Rama et al. fabricated a THz detector coupled with a split-bow-tie antenna on a $4 \mathrm{H}-$ $\mathrm{SiC}$ (0001) substrate [141]. The photovoltage of this device can be written as $\Delta \mathrm{U}=\Delta \mathrm{U}_{\mathrm{pwg}}+$ $\Delta \mathrm{U}_{\text {pte }}$, where $\Delta \mathrm{U}_{\mathrm{pwg}}$ is the voltage generated by the plasma effect, and its magnitude is determined by the conductivity and coupling efficiency of incident radiation to the antenna. The thermal effect generates a voltage, $\Delta \mathrm{U}_{\text {pte, }}$ whose magnitude is proportional to the conductivity. The change in conductivity is attributed to the change in carrier density. In order to obtain a large photovoltage, it is essential to choose graphene with high carrier mobility. However, the plasma effect plays a major role in the detection process. So, the energy coupled to the antenna is the most important in the design. By enhancing the antenna coupling efficiency, their device has a responsivity of $535 \mathrm{~V} / \mathrm{W}$ at a frequency of $0.8 \mathrm{THz}$, and the NEP is less than $100 \mathrm{pW} / \mathrm{Hz}^{1 / 2}$.

The resistance of the epitaxial growth graphene on $\mathrm{SiC}$ varies greatly with temperature due to quantum containment, so it has a high response rate $[136,142]$. Abdel El Fatimy et al. [107] used semi-insulating $6 \mathrm{H}-\mathrm{SiC}$ to synthesize graphene and made thermionic detectors by electron beam lithography. The detector performance is based on Joule heating. The responsivity of the detector is estimated according to the relationship diagram between resistance and electric power, which can reach $0.65 \times 10^{10} \mathrm{~V} / \mathrm{W}$ at $6 \mathrm{~K}$. Then, using the reverse wave oscillator on an incident $0.15 \mathrm{THz}$ electromagnetic wave, the detector has a response at $5 \times 10^{10} \mathrm{~V} / \mathrm{W}$, and the NEP is $2 \times 10^{-16} \mathrm{~W} / \mathrm{Hz}^{1 / 2}(2.5 \mathrm{~K})$. This noise power 
is evaluated based on the electrical characteristics and absorbed power of the pyrometer $\left(\mathrm{NEP}^{2}=\mathrm{NEP}_{\mathrm{JN}}^{2}+\mathrm{NEP}_{\mathrm{SN}}^{2}+\mathrm{NEP}_{\mathrm{TF}}^{2}\right.$, JN is Johnson-Nyquist noise, $\mathrm{SN}$ is hot noise, and TF is thermal fluctuations noise). Compared with the optical NEP measured by the incident power, the electrical NEP can directly reflect the intrinsic performance of the device without considering the antenna and measurement circuit. Using the detector coupled with a logperiodic antenna, the working range is increased to $0.7-4 \mathrm{THz}$. However, it is not clear whether the performance of the quantum dot detector is related to the higher frequency. In their subsequent work, the different wavelengths (from $\mathrm{THz}$ to ultraviolet light) are used to measured responsivity and calculate the total NEP, and the results show that the performance of the detector is completely independent of photon energy and the specific wavelength [143].

\section{Challenges and Future Perspective of Graphene Based Detectors}

Although many scholars have made progress on graphene $\mathrm{THz}$ detectors, there are still great challenges. For the preparation of graphene, the methods mentioned above have their limitations. The graphene produced by mechanical exfoliation has high quality, but the process is hard to control, and the produced graphene can hardly be mass-produced (with different areas and different layers), while large-area graphene also can hardly be produced. These limitations make it difficult to make the graphene $\mathrm{THz}$ detectors. The graphene synthesized by CVD can be controlled by changing the carbon source gas, deposition time, temperature, and other factors to control the size and layers of graphene [144]. Although the graphene produced by CVD has high quality, the synthesized graphene is attached to the surface of the metal substrates. They still need to be transferred to the insulating substrates before making the detector. During the transfer process, graphene could easily be contaminated or fragile, which remarkably influences the properties of graphene materials [145]. The most commonly used is the polymer-supported transfer method, which can completely transfer graphene to various substrates, but the etching solution and residual polymer contamination during the transfer process will damage the quality of the graphene and harmful to their mobility [146]. SiC epitaxial growth graphene can also control the size and number of layers. Comparing with CVD growth graphene, it is directly located on the $\mathrm{SiC}$ substrate and does not need a transfer. However, there is no dielectric isolation between the graphene and the substrate, and the charge of the substrate will affect the performance of the detector [147]. In addition, the harsh growth environment, high substrate price, low growth efficiency, and other factors make this method also difficult to achieve mass production in the near future.

There are also many challenges in the making of the graphene $\mathrm{THz}$ detector. For example, the detector is usually coupled with a metal antenna, but this will inevitably introduce some parasitic capacitance and increase the access resistance. When designing a specific antenna, scientists not only need to consider the size and type of the antenna but also need to take care of the impedance matching problem. Impedance mismatch will increase the NEP and RC time constants of the detection circuit [148]. When preparing the electrode, the material of the metal and the thickness of the electrode would also introduce impedance mismatch. Moreover, the contact interface between the metal and the graphene will also cause a step barrier due to their different work function, and the connection resistance in this area is also relatively high. In this case, it is not only necessary to avoid contamination and material degradation during the fabrication process, but it is also necessary to select the appropriate metal and thickness in order to lower the electrode's connection resistance [149]. In the bolometer, in order to improve the sensitivity, it is very necessary to choose a metal with small thermal resistance. The carrier mobility of graphene is limited by the substrate; choosing a high-quality substrate to fabricate the detector will reduce the influence of charged surface states and impurities, surface optical phonons, and substrate surface roughness [150]. Using $\mathrm{Al}_{2} \mathrm{O}_{3}$ or diamond instead of $\mathrm{SiO}_{2}$ as the substrate or encapsulating graphene with $\mathrm{hBN}$ may be employed in the future to develop GFET [151]. In addition, a standard process of electron beam lithography, dielectric layer 
deposition, graphene metal connection, and other steps in the device preparation process also need to be developed for making highly reliable graphene detectors.

Despite the challenges, there has been continuous progress in this field. CVD can prepare graphene materials with a large area and consistent performance with a single crystal and can use the direct transfer layer method to achieve clean and non-destructive transfer of graphene [152]. In addition, new structures of $\mathrm{THz}$ detectors have been continuously proposed $[103,112]$, which can meet the needs in different environments. The imaging system using the graphene $\mathrm{THz}$ detector can realize high-definition imaging, and the graphene FET can realize high-speed communication. They will play an important role in medical treatment, anti-terrorism, communications, and astronomical exploration in the future.

\section{Discussion and Conclusions}

In this review, we introduce the recent developments in graphene $\mathrm{THz}$ detectors. The review discussed the methods reported by researchers to improve the performance of $\mathrm{THz}$ detectors, which are based on graphene made by different methods. The performances of the detectors mentioned in the article are shown in Table 2.

Table 2. Performance parameters of graphene terahertz detectors mentioned in the article.

\begin{tabular}{|c|c|c|c|c|c|c|}
\hline Mechanism & $\begin{array}{c}\text { Graphene } \\
\text { Manufacturing } \\
\text { Method }\end{array}$ & $\begin{array}{l}\text { Working } \\
\text { Frequency }\end{array}$ & $\begin{array}{c}\text { Working } \\
\text { Temperature }\end{array}$ & NEP & Responsivity & Reference \\
\hline \multirow{2}{*}{ Bolometer } & SiC epitaxial growth & $0.3-1.6 \mathrm{THz}$ & $3 \mathrm{~K}$ & $5.6 \mathrm{pW} / \mathrm{Hz}^{1 / 2}$ & - & {$[66]$} \\
\hline & SiC epitaxial growth & $0.7-4 \mathrm{THz}$ & $2.5 \mathrm{~K}$ & $0.2 \mathrm{fW} / \mathrm{Hz}^{1 / 2}$ & $10^{10} \mathrm{~V} / \mathrm{W}$ & [107] \\
\hline PV & CVD & $2 \mathrm{THz}$ & RT & $150 \mathrm{nW} / \mathrm{Hz}^{1 / 2}$ & $34 \mu \mathrm{A} / \mathrm{W}$ & [73] \\
\hline \multirow{3}{*}{ PTE } & mechanical exfoliation & $1 \mathrm{THz}$ & RT & $100 \mathrm{pW} / \mathrm{Hz}^{1 / 2}$ & $10 \mathrm{~V} / \mathrm{W}$ & {$[74]$} \\
\hline & CVD & $0.11-0.3 \mathrm{THz}$ & $\mathrm{RT}$ & $0.35 \mathrm{nW} / \mathrm{Hz}^{1 / 2}$ & $28 \mathrm{~V} / \mathrm{W}$ & [75] \\
\hline & mechanical exfoliation & $1.8 \sim 4.2 \mathrm{THz}$ & RT & $80 \mathrm{pW} / \mathrm{Hz}^{1 / 2}$ & $105 \mathrm{~V} / \mathrm{W}$ & {$[72]$} \\
\hline \multirow{12}{*}{$\begin{array}{l}\text { Plasma wave } \\
\text { resonance }\end{array}$} & mechanical exfoliation & $0.3 \mathrm{THz}$ & RT & $30 \mathrm{nW} / \mathrm{Hz}^{1 / 2}$ & $0.15 \mathrm{~V} / \mathrm{W}$ & {$[122]$} \\
\hline & SiC epitaxial growth & $0.3-0.35 \mathrm{THz}$ & $\mathrm{RT}$ & $80 \mathrm{nW} / \mathrm{Hz}^{1 / 2}$ & $0.25 \mathrm{~V} / \mathrm{W}$ & [139] \\
\hline & SiC epitaxial growth & $0.2-0.65 \mathrm{THz}$ & RT & $1 \mathrm{nW} / \mathrm{Hz}^{1 / 2}$ & $2.65 \mathrm{~V} / \mathrm{W}$ & [101] \\
\hline & mechanical exfoliation & $1-3 \mathrm{THz}$ & $\mathrm{RT}$ & $1.7 \mathrm{nW} / \mathrm{Hz}^{1 / 2}$ & $4.9 \mathrm{~V} / \mathrm{W}$ & [100] \\
\hline & CVD & $0.6 \mathrm{THz}$ & RT & $515 \mathrm{pW} / \mathrm{Hz}^{1 / 2}$ & $14 \mathrm{~V} / \mathrm{W}$ & {$[134]$} \\
\hline & SiC epitaxial growth & $0.34 \mathrm{THz}$ & RT & $51 \mathrm{pW} / \mathrm{Hz}^{1 / 2}$ & $30 \mathrm{~V} / \mathrm{W}$ & {$[140]$} \\
\hline & CVD & $0.35 \mathrm{THz}$ & $\mathrm{RT}$ & $130 \mathrm{pW} / \mathrm{Hz}^{1 / 2}$ & $74 \mathrm{~V} / \mathrm{W}$ & [135] \\
\hline & - & $3 \mathrm{THz}$ & $77 \mathrm{~K}$ & $160 \mathrm{pW} / \mathrm{Hz}^{1 / 2}$ & $180 \mathrm{~V} / \mathrm{W}$ & [104] \\
\hline & CVD & $0.1-0.3 \mathrm{THz}$ & RT & $100 \mathrm{pW} / \mathrm{Hz}^{1 / 2}$ & $280 \mathrm{~V} / \mathrm{W}$ & [103] \\
\hline & mechanical exfoliation & $0.07-0.69 \mathrm{THz}$ & RT & $34 \mathrm{pW} / \mathrm{Hz}^{1 / 2}$ & $764 \mathrm{~V} / \mathrm{W}$ & [112] \\
\hline & mechanical exfoliation & $0.13 \mathrm{THz}$ & $10 \mathrm{~K}$ & $0.2 \mathrm{pW} / \mathrm{Hz}^{1 / 2}$ & $3000 \mathrm{~V} / \mathrm{W}$ & [67] \\
\hline & mechanical exfoliation & $0.13-2 \mathrm{THz}$ & $10 \mathrm{~K}$ & $0.1 \mathrm{pW} / \mathrm{Hz}^{1 / 2}$ & $3000 \mathrm{~V} / \mathrm{W}$ & [126] \\
\hline
\end{tabular}

Although the graphene $\mathrm{THz}$ detector has made a lot of progress in the laboratory, and they show many promising prospects comparing to traditional detectors, there is still a long way to go to achieve commercialization application. Moreover, the working range of these $\mathrm{THz}$ detectors is mostly at low-frequency $\mathrm{THz}$ waves, and high-frequency $\mathrm{THz}$ detectors are still difficult to achieve. These $\mathrm{THz}$ detectors with low equivalent noise power and high responsivity need to be realized in a low-temperature environment, and room temperature detectors still need to be further studied.

Author Contributions: Initiator of this manuscript, J.Z. (Jinfeng Zhu); writing-original draft preparation, J.L., J.Z. (Jinfeng Zhu); writing-review and editing, J.L., X.L., R.J., K.Y., J.Z. (Jing Zhao), S.A.K., J.H. and P.L.; supervision, B.Z.; project administration, B.Z.; funding acquisition, J.L. All authors have read and agreed to the published version of the manuscript.

Funding: This research was partially funded by National Nature Science Foundation of China (No. 61531010), Fundamental Research Funds for the Central Universities, and National Key Laboratory of Science and Technology on Vacuum Electronics (No. 6142807190205), NSAF (U1830116), Fujian 
Provincial Science and Technology Major Project (No. 2020HZ02014). Fujian Provincial Department of Science and Technology (2020J06009).

Conflicts of Interest: The authors declare no conflict of interest.

\section{References}

1. Liu, S.G. The new development of terahertz science and technology. Basic Sci. China 2006, 8, 7-12. [CrossRef]

2. Hu, B.B.; Nuss, M.C. Imaging with terahertz waves. Opt. Lett. 1995, 20, 1716. [CrossRef]

3. Seeds, A.J.; Williams, K.J. Microwave Photonics. J. Lightwave Technol. 2007, 24, 4628-4641. [CrossRef]

4. Tonouchi, M. Cutting-edge terahertz technology. Nat. Photonics 2007, 1, 97-105. [CrossRef]

5. Siegel, P.H. Terahertz Technology. IEEE Trans. Microw. Theory Tech. 2002, 50, 910-928. [CrossRef]

6. Cook, D.J.; Decker, B.K.; Maislin, G.; Allen, M.G.; Hwu, R.J. Through container THz sensing: Applications for explosives screening. Proc. SPIE 2004, 5354, 55-62.

7. Federici, J.F.; Schulkin, B.; Huang, F.; Gary, D.; Barat, R.; Oliveira, F.; Zimdars, D. THz imaging and sensing for security applications-Explosives, weapons and drugs. Semicond. Sci. Technol. 2005, 20, S266. [CrossRef]

8. Han, P.Y.; Chen, J.; Zhao, H.W.; Schulkin, B.; Chen, Y.Q.; Bastiaans, G.; Warrender, J.; Zhang, X.C. Application of Terahertz Spectroscopy in Security, Chemistry \& Microscopy. Presented at the Laser Applications to Chemical, Security and Environmental Analysis, St. Petersburg, FL, USA, 17 March 2008.

9. Woodward, R. Terahertz pulse imaging in reflection geometry of human skin cancer and skin tissue. Phys. Med. Biol. 2002, 47, 3853. [CrossRef] [PubMed]

10. Yalcin, A.; Popat, K.C.; Aldridge, J.C.; Desai, T.A.; Hryniewicz, J.; Chbouki, N.; Little, B.E.; King, O.; Van, V.; Chu, S. Optical sensing of biomolecules using microring resonators. IEEE J. Sel. Top. Quantum Electron. 2016, 12, 148-155. [CrossRef]

11. Rogalski, A.; Sizov, F. Terahertz detectors and focal plane arrays. Opto-Electron. Rev. 2011, 19, 346-404. [CrossRef]

12. Hu, F.; Lucyszyn, S. Modelling Miniature Incandescent Light Bulbs for Thermal Infrared 'THz Torch' Applications. J. Infrared Millim. Terahertz Waves 2015, 36, 350-367. [CrossRef]

13. Seliverstov, S.; Maslennikov, S.; Ryabchun, S.; Finkel, M.; Klapwijk, T.M.; Kaurova, N.; Vachtomin, Y.; Smirnov, K.; Voronov, B.; Gol"Tsman, G. Fast and Sensitive Terahertz Direct Detector Based on Superconducting Antenna-Coupled Hot Electron Bolometer. IEEE Trans. Appl. Supercond. 2015, 25, 1-4. [CrossRef]

14. Timofeev, A.; Luomahaara, J.; Gronberg, L.; Mayra, A.; Sipola, H.; Aikio, M.; Metso, M.; Vesterinen, V.; Tappura, K.; Ala-Laurinaho, J. Optical and Electrical Characterization of a Large Kinetic Inductance Bolometer Focal Plane Array. IEEE Trans. Terahertz Sci. Technol. 2017, PP, 1-7. [CrossRef]

15. Wu, C.; Zhou, W.; Yao, N.; Xu, X.; Qu, Y.; Zhang, Z.; Wu, J.; Jiang, L.; Huang, Z.; Chu, J. Silicon-based high sensitivity of room-temperature microwave and sub-terahertz detector. Appl. Phys. Express 2019, 12, 052013. [CrossRef]

16. Hu, F.; Sun, J.; Brindley, H.E.; Liang, X.; Lucyszyn, S. Systems Analysis for Thermal Infrared 'THz Torch' Applications. J. Infrared Millim. Terahertz Waves 2015, 36, 474-495. [CrossRef]

17. Li, W.; Liang, Z.; Wang, J.; Gou, J.; Jiang, Y. A direct method of thermal time constant measurement for lithium tantalate based terahertz pryroelectric detectors. J. Mater. Sci. Mater. Electron. 2016, 27, 9996-10002. [CrossRef]

18. Müller, R.; Gutschwager, B.; Hollandt, J.; Kehrt, M.; Monte, C.; Müller, R.; Steiger, A. Characterization of a Large-Area Pyroelectric Detector from 300GHz to 30THz. J. Infrared Millim. Terahertz Waves 2015, 36, 654-661. [CrossRef]

19. Yamashita, K.; Murata, A.; Okuyama, M. Golay-cell type of miniaturized infrared sensor using Si-diaphragm. Presented at the International Solid State Sensors and Actuators Conference (Transducers '97), Chicago, IL, USA, 19 June 1997.

20. Schlecht, M.T.; Preu, S.; Malzer, S.; Weber, H.B. An efficient Terahertz rectifier on the graphene/SiC materials platform. Sci. Rep. 2019, 9, 11205. [CrossRef] [PubMed]

21. Liang, S.; Sheng, H.; Liu, Y.; Huo, Z.; Lu, Y.; Shen, H. ZnO Schottky ultraviolet photodetectors. J. Cryst. Growth 2001, 225, 110-113. [CrossRef]

22. Sakhno, M.; Golenkov, A.; Sizov, F. Uncooled detector challenges: Millimeter-wave and terahertz long channel field effect transistor and Schottky barrier diode detectors. J. Appl. Phys. 2013, 114, 164503. [CrossRef]

23. Tauk, R.; Teppe, F.; Boubanga, S.; Coquillat, D.; Knap, W.; Meziani, Y.M.; Gallon, C.; Boeuf, F.; Skotnicki, T.; Fenouillet-Beranger, C.; et al. Plasma wave detection of terahertz radiation by silicon field effects transistors: Responsivity and noise equivalent power. Appl. Phys. Lett. 2006, 89, 253511. [CrossRef]

24. Javadi, E.; But, D.B.; Ikamas, K.; Zdanevičius, J.; Knap, W.; Lisauskas, A. Sensitivity of Field-Effect Transistor-Based Terahertz Detectors. Sensors 2021, 21, 2909. [CrossRef]

25. Suziedelis, A.; Gradauskas, J.; Asmontas, S.; Valusis, G.; Roskos, H.G. Giga- and terahertz frequency band detector based on an asymmetrically necked n-n+-GaAs planar structure. J. Appl. Phys. 2003, 93, 3034-3038. [CrossRef]

26. Kasalynas, I.; Seliuta, D.; Simniskis, R.; Tamosiunas, V.; Koehler, K.; Valusis, G. Terahertz imaging with bow-tie InGaAs-based diode with broken symmetry. Electron. Lett. 2009, 45, 833-835. [CrossRef]

27. Seliuta, D.; Kasalynas, I.; Tamosiunas, V.; Balakauskas, S.; Martunas, Z.; Asmontas, S.; Valusis, G.; Lisauskas, A.; Roskos, H.G.; Kohler, K. Silicon lens-coupled bow-tie InGaAs-based broadband terahertz sensor operating at room temperature. Electron. Lett. 2006, 42, 825-827. [CrossRef] 
28. Kosarev, A.; Rumyantsev, S.; Moreno, M.; Torres, A.; Boubanga, S.; Knap, W. SixGey:H-based micro-bolometers studied in the terahertz frequency range. Solid State Electron. 2010, 54, 417-419. [CrossRef]

29. Ajakaiye, O.; Grade, J.; Shin, C.; Kenny, T. Wafer-scale fabrication of infrared detectors based on tunneling displacement transducers. Sens. Actuators A Phys. 2007, 134, 575-581. [CrossRef]

30. Rogalski, A. Terahertz detectors and focal plane arrays. Elektronika 2010, 51, 93-108.

31. Vitiello, M.S. Semiconductor nanowires for highly sensitive, room-temperature detection of terahertz quantum cascade laser emission. Appl. Phys. Lett. 2012, 100, 97. [CrossRef]

32. Preu, S.; Mittendorff, M.; Winnerl, S.; Lu, H.; Gossard, A.C.; Weber, H.B. Ultra-fast transistor-based detectors for precise timing of near infrared and THz signals. Opt. Express 2013, 21, 17941-17950. [CrossRef]

33. Liu, Z.; Liang, Z.; Tang, W.; Xu, X. Design and fabrication of low-deformation micro-bolometers for THz detectors. Infrared Phys. Technol. 2020, 105, 103241. [CrossRef]

34. Theocharous, S.P.; Theocharous, E.; Lehman, J.H. The evaluation of the performance of two pyroelectric detectors with vertically aligned multi-walled carbon nanotube coatings. Infrared Phys. Technol. 2012, 55, 299-305. [CrossRef]

35. Stefanova, P.S.; Hammler, J.M.; Klein, A.K.; Gallant, A.J.; Balocco, C. Polymer-based micro-golay cells for THz detection. Presented at the 2016 41st International Conference on Infrared, Millimeter, and Terahertz Waves (IRMMW-THz), Copenhagen, Denmark, 25-30 September 2016.

36. Daghestani, N.; Parow-Souchon, K.; Pardo, D.; Liu, H.; Brewster, N.; Frogley, M.; Cinque, G.; Alderman, B.; Huggard, P.G. Room temperature ultrafast InGaAs Schottky diode based detectors for terahertz spectroscopy. Infrared Phys. Technol. 2019, 99, 240-247. [CrossRef]

37. Chen, H.; Padilla, W.; Zide, J.; Gossard, A.; Taylor, A.; Averitt, R. Active terahertz metamaterial devices. Nature 2006, 444, 597-600. [CrossRef]

38. Guo, W.; Dong, Z.; Xu, Y.; Liu, C.; Wei, D.; Zhang, L.; Shi, X.; Guo, C.; Xu, H.; Chen, G.; et al. Sensitive Terahertz Detection and Imaging Driven by the Photothermoelectric Effect in Ultrashort-Channel Black Phosphorus Devices. Adv. Sci. 2020, 7, 1902699. [CrossRef]

39. Zhang, Y.; Li, H.; Wang, L.; Wang, H.; Xie, X.; Zhang, S.-L.; Liu, R.; Qiu, Z.-J. Photothermoelectric and photovoltaic effects both present in MoS2. Sci. Rep. 2015, 5, 7938. [CrossRef]

40. Novoselov, K.S.; Geim, A.K.; Morozov, S.V.; Jiang, D.; Zhang, Y.; Dubonos, S.V.; Grigorieva, I.V.; Firsov, A.A. Electric Field Effect in Atomically Thin Carbon Films. Science 2004, 306, 666-669. [CrossRef] [PubMed]

41. Allen, M.J.; Tung, V.C.; Kaner, R.B. Honeycomb Carbon: A Review of Graphene. Chem. Rev. 2010, 110, 132-145. [CrossRef]

42. Geim, A.K.; Novoselov, K.S. The rise of graphene. Nat. Mater. 2009, 6, 11-19.

43. Castro Neto, A.H.; Guinea, F.; Peres, N.M.R.; Novoselov, K.S.; Geim, A.K. The electronic properties of graphene. Rev. Mod. Phys. 2009, 81, 109-162. [CrossRef]

44. Bolotin, K.I.; Sikes, K.J.; Jiang, Z.; Klima, M.; Fudenberg, G.; Hone, J.; Kim, P.; Stormer, H.L. Ultrahigh electron mobility in suspended graphene. Solid State Commun. 2008, 146, 351-355. [CrossRef]

45. Balandin, A.A. Thermal properties of graphene and nanostructured carbon materials. Nat. Mater. 2011, 10, 569-581. [CrossRef] [PubMed]

46. Pei, Z.; Chauhan, J.; Jing, G. Computational Study of Tunneling Transistor Based on Graphene Nanoribbon. Nano Lett. 2009, 9 , 684-688.

47. Eda, G.; Chhowalla, M. Graphene-based composite thin films for electronics. Nano Lett. 2009, 9, 814-818. [CrossRef] [PubMed]

48. Zhang, Y.; Du, J.; Tang, S.; Liu, P.; Deng, S.; Chen, J.; Xu, N. Optimize the field emission character of a vertical few-layer graphene sheet by manipulating the morphology. Nanotechnology 2011, 23, 015202. [CrossRef]

49. Kawano, Y. Wide-band frequency-tunable terahertz and infrared detection with graphene. Nanotechnology 2013, $24,214004$. [CrossRef]

50. Müller, R.; Bohmeyer, W.; Kehrt, M.; Lange, K.; Monte, C.; Steiger, A. Novel detectors for traceable THz power measurements. J. Infrared Millim. Terahertz Waves 2014, 35, 659-670. [CrossRef]

51. Dawlaty, J.M.; Shivaraman, S.; Strait, J.; George, P.; Chandrashekhar, M.; Rana, F.; Spencer, M.G.; Veksler, D.; Chen, Y. Measurement of the Optical Absorption Spectra of Epitaxial Graphene from Terahertz to Visible. Appl. Phys. Lett. 2008, 93, 131905. [CrossRef]

52. Pinto, S.; Krishna, R.; Dias, C.; Pimentel, G.; Oliveira, G.N.P.; Teixeira, J.M.; Aguiar, P.; Titus, E.; Gracio, J.; Ventura, J. Resistive switching and activity-dependent modifications in Ni-doped graphene oxide thin films. Appl. Phys. Lett. 2012, $101,2632$. [CrossRef]

53. Wang, F.; Zhang, Y.; Tian, C.; Girit, C.; Zettl, A.; Crommie, M.; Shen, Y.R. Gate-variable optical transitions in graphene. Science 2008, 320, 206-209. [CrossRef]

54. Neto, A.; Guinea, F.; Peres, N.; Novoselov, K.S.; Geim, A. The electronic properties of graphene and its bilayer. Vacuum 2009, 83, 1248-1252.

55. Makaram, P.; Joh, J.; Alamo, J.A.D.; Palacios, T.; Thompson, C.V. Evolution of structural defects associated with electrical degradation in AlGaN/GaN high electron mobility transistors. Appl. Phys. Lett. 2010, 96, 756-758. [CrossRef]

56. Mckitterick, C.B.; Prober, D.E.; Karasik, B.S. Performance of Graphene Thermal Photon Detectors. J. Appl. Phys. 2013, 113, 379. [CrossRef] 
57. Yan, J.; Kim, M.H.; Elle, J.A.; Sushkov, A.B.; Jenkins, G.S.; Milchberg, H.M.; Fuhrer, M.S.; Drew, H.D. Dual-gated bilayer graphene hot-electron bolometer. Nat. Nanotechnol. 2012, 7, 472-478. [CrossRef]

58. Lee, G.-H.; Efetov, D.K.; Jung, W.; Ranzani, L.; Walsh, E.D.; Ohki, T.A.; Taniguchi, T.; Watanabe, K.; Kim, P.; Englund, D.; et al. Graphene-based Josephson junction microwave bolometer. Nature 2020, 586, 42-46. [CrossRef]

59. Ryzhii, V.; Otsuji, T.; Ryzhii, M.; Ryabova, N.; Yurchenko, S.O.; Mitin, V.; Shur, M.S. Graphene terahertz uncooled bolometers. J. Phys. D Appl. Phys. 2012, 46, 065102. [CrossRef]

60. Dicke, R.H. The Measurement of Thermal Radiation at Microwave Frequencies; Springer: Dordrecht, The Netherlands, 1982.

61. Li, J.; Zhao, Y.; Tang, L.; Nie, C.; Yao, W. A Polarization-Sensitive Multiband Plasmonic Hot Electron Photodetector Based on Conformal MoS. J. Nanosci. Nanotechnol. 2019, 19, 213-219. [CrossRef] [PubMed]

62. Wu, K.; Zhan, Y.; Zhang, C.; Wu, S.; Li, X. Strong and highly asymmetrical optical absorption in conformal metal-semiconductormetal grating system for plasmonic hot-electron photodetection application. Sci. Rep. 2015, 5, 14304. [CrossRef]

63. Mckitterick, C.B.; Vora, H.; Du, X.; Karasik, B.S.; Prober, D.E. Graphene Microbolometers with Superconducting Contacts for Terahertz Photon Detection. J. Low Temp. Phys. 2014, 176, 291-298. [CrossRef]

64. Betz, A.C.; Vialla, F.; Brunel, D.; Voisin, C.; Picher, M.; Cavanna, A.; Madouri, A.; Fève, G.; Berroir, J.M.; Plaçais, B.; et al. Hot Electron Cooling by Acoustic Phonons in Graphene. Phys. Rev. Lett. 2012, 109, 056805. [CrossRef]

65. Fong, K.C.; Schwab, K.C. Ultrasensitive and Wide-Bandwidth Thermal Measurements of Graphene at Low Temperatures. Phys. Rev. X 2012, 2, 031006. [CrossRef]

66. Miao, W.; Gao, H.; Wang, Z.; Zhang, W.; Ren, Y.; Zhou, K.M.; Shi, S.C.; Yu, C.; He, Z.Z.; Liu, Q.B. A Graphene-Based Terahertz Hot Electron Bolometer with Johnson Noise Readout. J. Low Temp. Phys. 2018, 193, 387-392. [CrossRef]

67. Gayduchenko, I.; Xu, S.G.; Alymov, G.; Moskotin, M.; Tretyakov, I.; Taniguchi, T.; Watanabe, K.; Goltsman, G.; Geim, A.K.; Fedorov, G.; et al. Tunnel field-effect transistors for sensitive terahertz detection. Nat. Commun. 2021, 12, 543. [CrossRef]

68. Tomadin, A.; Tredicucci, A.; Pellegrini, V.; Vitiello, M.S.; Polini, M. Photocurrent-Based detection of Terahertz radiation in graphene. Appl. Phys. Lett. 2013, 103, 211120. [CrossRef]

69. Kawano, Y.; Ishibashi, K. Wide-band frequency-selective terahertz detection based on a single-layer graphene. Presented at the 2009 34th International Conference on Infrared, Millimeter, and Terahertz Waves, Busan, Korea, 21-25 September 2009.

70. Tan, R.B.; Qin, H.; Sun, J.D.; Zhang, X.Y.; Zhang, B.S. Modeling an antenna-coupled graphene field-effect terahertz detector. Appl. Phys. Lett. 2013, 103, 143. [CrossRef]

71. Song, J.C.W.; Rudner, M.S.; Marcus, C.M.; Levitov, L.S. Hot Carrier Transport and Photocurrent Response in Graphene. Nano Lett. 2011, 11, 4688-4692. [CrossRef]

72. Castilla, S.; Terrés, B.; Autore, M.; Viti, L.; Li, J.; Nikitin, A.Y.; Vangelidis, I.; Watanabe, K.; Taniguchi, T.; Lidorikis, E.; et al. Fast and Sensitive Terahertz Detection Using an Antenna-Integrated Graphene pn Junction. Nano Lett. 2019, 19, 2765-2773. [CrossRef]

73. Degl'Innocenti, R.; Xiao, L.; Jessop, D.S.; Kindness, S.J.; Ren, Y.; Lin, H.; Zeitler, J.A.; Alexander-Webber, J.A.; Joyce, H.J.; Braeuninger-Weimer, P. Fast Room-Temperature Detection of Terahertz Quantum Cascade Lasers with Graphene-Loaded Bow-Tie Plasmonic Antenna Arrays. ACS Photonics 2016, 3, 1747-1753. [CrossRef]

74. Cai, X.; Sushkov, A.B.; Suess, R.J.; Jadidi, M.M.; Jenkins, G.S.; Nyakiti, L.O.; Myers-Ward, R.L.; Li, S.; Yan, J.; Gaskill, D.K.; et al. Sensitive room-temperature terahertz detection via the photothermoelectric effect in graphene. Nat. Nanotechnol. 2014, 9, 814-819. [CrossRef]

75. Wanlong, G.; Lin, W.; Xiaoshuang, C.; Changlong, L.; Weiwei, T.; Cheng, G.; Jin, W.; Wei, L. Graphene-based broadband terahertz detector integrated with a square-spiral antenna. Opt. Lett. 2018, 43, 1647-1650.

76. Xu, Y.Y.; Xu, Y.; Hu, J.; Yin, W.Y. Design of a novel reconfigurable Sierpinski fractal graphene antenna operating at THz band. Presented at the 2013 IEEE International Symposium on Antennas and Propagation \& USNC/URSI National Radio Science Meeting, Orlando, FL, USA, 7-13 July 2013.

77. Hong, S.K.; Jeon, S.C.; Hwang, W.S.; Cho, B.J. Resistance analysis and device design guideline for graphene RF transistors. 2D Materials 2015, 2, 034011. [CrossRef]

78. Huang, Z.; Han, Q.; Ji, C.; Wang, J.; Jiang, Y. Broadband terahertz modulator based on graphene metamaterials. AIP Adv. 2018, 8, 035304. [CrossRef]

79. Borzooei, S.; Rezagholizadeh, E.; Biabanifard, M. Graphene disks for frequency control of terahertz waves in broadband applications. J. Comput. Electron. 2020, 19, 1-4. [CrossRef]

80. Yi, Z.; Chen, J.; Cen, C.; Chen, X.; Zhou, Z.; Tang, Y.; Ye, X.; Xiao, S.; Luo, W.; Wu, P. Tunable Graphene-based Plasmonic Perfect Metamaterial Absorber in the THz Region. Micromachines 2019, 10, 194. [CrossRef] [PubMed]

81. Amirmazlaghani, M.; Raissi, F. Feasibility of Room-Temperature GHz-THz Direct Detection in Graphene Through Hot-Carrier Effect. IEEE Trans. Device Mater. Reliab. 2018, 18, 429-437. [CrossRef]

82. Li, Y.; Zhang, Y.; Yu, Y.; Chen, Z.; Yao, J.Q. Ultraviolet-to-Microwave Room Temperature Photodetectors Based on Threedimensional Graphene Foams. Photonics Res. 2020, 8, 368-374. [CrossRef]

83. Chen, M.; Wang, Y.; Wen, J.; Chen, H.; Ma, W.; Fan, F.; Huang, Y.; Zhao, Z. Annealing Temperature-Dependent Terahertz Thermal-Electrical Conversion Characteristics of Three-Dimensional Microporous Graphene. ACS Appl. Mater. Interfaces 2019, 11, 6411-6420. [CrossRef] [PubMed]

84. Dyakonov, M.; Shur, M. Shallow water analogy for a ballistic field effect transistor: New mechanism of plasma wave generation by dc current. Phys. Rev. Lett. 1993, 71, 2465-2468. [CrossRef] [PubMed] 
85. Knap, W.; Dyakonov, M.; Coquillat, D.; Teppe, F.; Dyakonova, N.; Łusakowski, J.; Karpierz, K.; Sakowicz, M.; Valusis, G.; Seliuta, D.; et al. Field Effect Transistors for Terahertz Detection: Physics and First Imaging Applications. J. Infrared Millim. Terahertz Waves 2009, 30, 1319-1337. [CrossRef]

86. Teppe, F.; Orlov, M.; El Fatimy, A.; Tiberj, A.; Knap, W.; Torres, J.; Gavrilenko, V.; Shchepetov, A.; Roelens, Y.; Bollaert, S. Room temperature tunable detection of subterahertz radiation by plasma waves in nanometer InGaAs transistors. Appl. Phys. Lett. 2006 89, 222109. [CrossRef]

87. Meziani, Y.M.; Hanabe, M.; Koizumi, A.; Otsuji, T.; Sano, E. Self Oscillation of the Plasma Waves in a Dual Grating Gates HEMT Device. Presented at the IEEE International Conference on Indium Phosphide \& Related Materials, Matsue, Japan, 14-18 May 2007.

88. Soltani, A.; Kuschewski, F.; Bonmann, M.; Generalov, A.; Roskos, H.G. Direct nanoscopic observation of plasma waves in the channel of a graphene field-effect transistor. Light Sci. Appl. 2020, 9, 97. [CrossRef] [PubMed]

89. Sun, J. Field-Effect Self-Mixing Mechanism and Detector Model. In Field-Effect Self-Mixing Terahertz Detectors; Sun, J., Ed.; Springer: Berlin/Heidelberg, Germany, 2016; pp. 19-39. [CrossRef]

90. Jadidi, M.M.; Sushkov, A.; Myers-Ward, R.L.; Boyd, A.; Daniels, K.; Gaskill, D.K.; Fuhrer, M.S.; Drew, H.D.; Murphy, T.E. Tunable Terahertz Hybrid Metal-Graphene Plasmons. Nano Lett. 2015, 15, 7099-7104. [CrossRef]

91. Rana, F. Graphene Terahertz Plasmon Oscillators. IEEE Trans. Nanotechnol. 2008, 7, 91-99. [CrossRef]

92. Wang, L.; Chen, X.; Yu, A.; Zhang, Y.; Ding, J.; Lu, W. Highly Sensitive and Wide-Band Tunable Terahertz Response of Plasma Waves Based on Graphene Field Effect Transistors. Sci. Rep. 2014, 4, 5470. [CrossRef]

93. Novoselov, K.S.; Geim, A.K.; Morozov, S.V.; Jiang, D.; Katsnelson, M.I.; Grigorieva, I.V.; Dubonos, S.V.; Firsov, A.A. Twodimensional gas of massless Dirac fermions in graphene. Nature 2005, 438, 197-200. [CrossRef]

94. Echtermeyer, T.J.; Lemme, M.C.; Bolten, J.; Baus, M.; Ramsteiner, M.; Kurz, H. A Graphene Field-Effect Device. Eur. Phys. J. Spec. Top. 2007, 148, 19-26. [CrossRef]

95. Ryzhii, V.; Ryzhii, M. Graphene bilayer field-effect phototransistor for terahertz and infrared detection. Phys. Rev. B 2009, 79, 245311. [CrossRef]

96. Lin, Y.M.; Dimitrakopoulos, C.; Jenkins, K.A.; Farmer, D.B.; Chiu, H.Y.; Grill, A.; Avouris, P. 100-GHz transistors from wafer-scale epitaxial graphene. Science 2010, 327, 662. [CrossRef]

97. Lin, Y.M.; Valdes-Garcia, A.; Han, S.J.; Farmer, D.B.; Meric, I.; Sun, V.; Wu, Y.; Dimitrakopoulos, C.; Grill, A.; Avouris, P. Wafer-Scale Graphene Integrated Circuit. Science 2011, 332, 1294-1297. [CrossRef] [PubMed]

98. Zhang, W.; Phi, H.Q.P.; Brown, E.R.; Burke, P.J. AC conductivity parameters of graphene derived from THz etalon transmittance. Nanoscale 2014, 6, 13895-13899. [CrossRef]

99. Sizov, F.; Rogalski, A. THz detectors. Prog. Quantum Electron. 2010, 34, 278-347. [CrossRef]

100. Tong, J.; Muthee, M.; Chen, S.Y.; Yngvesson, S.K.; Yan, J. Antenna enhanced graphene THz emitter and detector. Nano Lett. 2015, 15, 5295. [CrossRef]

101. Qin, H.; Sun, J.; He, Z.; Li, X.; Li, X.; Liang, S.; Yu, C.; Feng, Z.; Tu, X.; Jin, B.; et al. Heterodyne detection at 216, 432, and 648 GHz based on bilayer graphene field-effect transistor with quasi-optical coupling. Carbon 2017, 121, 235-241. [CrossRef]

102. Mittendorff, M.; Winnerl, S.; Kamann, J.; Eroms, J.; Weiss, D.; Schneider, H.; Helm, M. Ultrafast graphene-based broadband THz detector. Appl. Phys. Lett. 2013, 103, 666. [CrossRef]

103. Liu, C.; Du, L.; Tang, W.; Wei, D.; Li, J.; Wang, L.; Chen, G.; Chen, X.; Lu, W. Towards sensitive terahertz detection via thermoelectric manipulation using graphene transistors. NPG Asia Mater. 2018, 10, 318-327. [CrossRef]

104. Viti, L.; Purdie, D.G.; Lombardo, A.; Ferrari, A.C.; Vitiello, M.S. HBN-encapsulated, graphene-based room-temperature terahertz receivers with high speed and low noise. Nano Lett. 2020, 20, 3169-3177. [CrossRef] [PubMed]

105. Novotny, L.; Van Hulst, N. Antennas for light. Nat. Photonics 2011, 5, 83-90. [CrossRef]

106. Sensale-Rodriguez, B. Graphene-insulator-graphene active plasmonic terahertz devices. Appl. Phys. Lett. 2013, 103, 123109. [CrossRef]

107. Fatimy, A.E.; Myers-Ward, R.L.; Boyd, A.K.; Daniels, K.M.; Gaskill, D.K.; Barbara, P. Epitaxial graphene quantum dots for high-performance THz bolometers. arXiv 2015, arXiv:1509.04646.

108. Cai, X.; Sushkov, A.B.; Jadidi, M.M.; Nyakiti, L.O.; Myers-Ward, R.L.; Gaskill, D.K.; Murphy, T.E.; Fuhrer, M.S.; Drew, H.D. Plasmon-Enhanced Terahertz Photodetection in Graphene. Nano Lett. 2015, 15, 4295-4302. [CrossRef] [PubMed]

109. Mikhailov, S.A.; Savostianova, N.A. Influence of contacts on the microwave response of a two-dimensional electron stripe. Phys. Rev. B Condens. Matter Mater. Phys. 2006, 74, 045325. [CrossRef]

110. Drexler, C.; Dyakonova, N.; Olbrich, P.; Karch, J.; Schafberger, M.; Karpierz, K.; Mityagin, Y.; Lifshits, M.B.; Teppe, F.; Klimenko, O. Helicity sensitive terahertz radiation detection by field effect transistors. J. Appl. Phys. 2012, 111, 380-2833. [CrossRef]

111. Matyushkin, Y.; Danilov, S.; Moskotin, M.; Belosevich, V.; Kaurova, N.; Rybin, M.; Obraztsova, E.D.; Fedorov, G.; Gorbenko, I.; Kachorovskii, V.; et al. Helicity-Sensitive Plasmonic Terahertz Interferometer. Nano Lett. 2020, 20, 7296-7303. [CrossRef]

112. Auton, G.; But, D.B.; Zhang, J.; Hill, E.; Coquillat, D.; Consejo, C.; Nouvel, P.; Knap, W.; Varani, L.; Teppe, F.; et al. Terahertz Detection and Imaging Using Graphene Ballistic Rectifiers. Nano Lett. 2017, 17, 7015-7020. [CrossRef]

113. Hackley, J.; Ali, D.; Dipasquale, J.; Demaree, J.D.; Richardson, C.J.K. Graphitic carbon growth on Si(111) using solid source molecular beam epitaxy. Appl. Phys. Lett. 2009, 95, 133114. [CrossRef] 
114. Hernandez, Y.; Nicolosi, V.; Lotya, M.; Blighe, F.M.; Sun, Z.; De, S.; McGovern, I.T.; Holland, B.; Byrne, M.; Gun'Ko, Y.K.; et al. High-yield production of graphene by liquid-phase exfoliation of graphite. Nat. Nanotechnol. 2008, 3, 563-568. [CrossRef]

115. Blake, P.; Brimicombe, P.D.; Nair, R.R.; Booth, T.J.; Jiang, D.; Schedin, F.; Ponomarenko, L.A.; Morozov, S.V.; Gleeson, H.F.; Hill, E.W.; et al. Graphene-Based Liquid Crystal Device. Nano Lett. 2008, 8, 1704-1708. [CrossRef] [PubMed]

116. Casiraghi, C.; Pisana, S.; Novoselov, K.S.; Geim, A.K.; Ferrari, A.C. Raman fingerprint of charged impurities in graphene. Appl. Phys. Lett. 2007, 91, 183. [CrossRef]

117. Novoselov, K.S.; Fal'Ko, V.I.; Colombo, L.; Gellert, P.R.; Kim, K.A. A Roadmap for graphene. Nature 2012, 490, 192-200. [CrossRef]

118. Novoselov, K.S.; Jiang, D.; Schedin, F.; Booth, T.J.; Khotkevich, V.V.; Morozov, S.V.; Geim, A.K. Two-dimensional atomic crystals. Proc. Natl. Acad. Sci. USA 2005, 102, 10451-10453. [CrossRef]

119. Liang, X.; Fu, Z.; Chou, S.Y. Graphene Transistors Fabricated via Transfer-Printing In Device Active-Areas on Large Wafer. Nano Lett. 2007, 7, 3840-3844. [CrossRef]

120. Zhang, Y.; Small, J.P.; Pontius, W.V.; Kim, P. Fabrication and electric-field-dependent transport measurements of mesoscopic graphite devices. Appl. Phys. Lett. 2005, 86, 073104. [CrossRef]

121. Xuan, Y.; Wu, Y.Q.; Shen, T.; Qi, M.; Capano, M.A.; Cooper, J.A.; Ye, P.D. Atomic-layer-deposited nanostructures for graphenebased nanoelectronics. Appl. Phys. Lett. 2008, 92, 013101. [CrossRef]

122. Vicarelli, L.; Vitiello, M.S.; Coquillat, D.; Lombardo, A.; Ferrari, A.C.; Knap, W.; Polini, M.; Pellegrini, V.; Tredicucci, A. Graphene field-effect transistors as room-temperature terahertz detectors. Nat. Mater. 2012, 11, 865-871. [CrossRef]

123. Vitiello, M.S.; Coquillat, D.; Viti, L.; Ercolani, D.; Teppe, F.; Pitanti, A.; Beltram, F.; Sorba, L.; Knap, W.; Tredicucci, A. Roomtemperature terahertz detectors based on semiconductor nanowire field-effect transistors. Nano Lett 2012, 12, 96-101. [CrossRef] [PubMed]

124. Liao, L.; Lin, Y.C.; Bao, M.; Cheng, R.; Bai, J.; Liu, Y.; Qu, Y.; Wang, K.L.; Huang, Y.; Duan, X. High-speed graphene transistors with a self-aligned nanowire gate. Nature 2010, 467, 305-308. [CrossRef]

125. Kretinin, A.V.; Cao, Y.; Tu, J.S.; Yu, G.L.; Jalil, R.; Novoselov, K.S.; Haigh, S.J.; Gholinia, A.; Mishchenko, A.; Lozada, M.; et al. Electronic Properties of Graphene Encapsulated with Different Two-Dimensional Atomic Crystals. Nano Lett. 2014, 14, 3270-3276. [CrossRef]

126. Bandurin, D.A.; Svintsov, D.; Gayduchenko, I.; Xu, S.G.; Principi, A.; Moskotin, M.; Tretyakov, I.; Yagodkin, D.; Zhukov, S.; Taniguchi, T.; et al. Resonant terahertz detection using graphene plasmons. Nat. Commun. 2018, 9, 5392. [CrossRef]

127. Yu, Q.; Lian, J.; Siriponglert, S.; Li, H.; Chen, Y.P.; Pei, S.S. Graphene segregated on Ni surfaces and transferred to insulators. Appl. Phys. Lett. 2008, 93, 183. [CrossRef]

128. Li, X.; Cai, W.; An, J.; Kim, S.; Nah, J.; Yang, D.; Piner, R.; Velamakanni, A.; Jung, I.; Tutuc, E.; et al. Large-area synthesis of high-quality and uniform graphene films on copper foils. Science 2009, 324, 1312-1314. [CrossRef] [PubMed]

129. Pandey, S.; Rai, P.; Patole, S.; Gunes, F.; Kwon, G.D.; Yoo, J.B.; Nikolaev, P.; Arepalli, S. Improved electron field emission from morphologically disordered monolayer graphene. Appl. Phys. Lett. 2012, 100, 1179. [CrossRef]

130. Malesevic, A.; Kemps, R.; Vanhulsel, A.; Chowdhury, M.P.; Volodin, A.; Haesendonck, C.V. Field emission from vertically aligned few-layer graphene. J. Appl. Phys. 2008, 104, 666. [CrossRef]

131. Behura, S.K.; Mukhopadhyay, I.; Hirose, A.; Yang, Q.; Jani, O. Vertically oriented few-layer graphene as an electron field-emitter. Phys. Status Solidi (a) 2013, 210, 1817-1821. [CrossRef]

132. Shakil, A.; Amiri, A.; Tang, H.; Polycarpou, A.A. High temperature nanomechanical and nanotribological behavior of sub-5 nm nitrogen-doped carbon overcoat films. Appl. Surf. Sci. 2020, 535, 147662. [CrossRef]

133. Schmitz, M.; Engels, S.; Banszerus, L.; Watanabe, K.; Taniguchi, T.; Stampfer, C.; Beschoten, B. High mobility dry-transferred CVD bilayer graphene. Appl. Phys. Lett. 2017, 110, 263110. [CrossRef]

134. Zak, A.; Andersson, M.A.; Bauer, M.; Matukas, J.; Lisauskas, A.; Roskos, H.G.; Stake, J. Antenna-integrated 0.6 THz FET direct detectors based on CVD graphene. Nano Lett. 2014, 14, 5834-5838. [CrossRef]

135. Generalov, A.A.; Andersson, M.A.; Yang, X.; Vorobiev, A.; Stake, J. A 400-GHz Graphene FET Detector. IEEE Trans. Terahertz Sci. Technol. 2017, 7, 614-616. [CrossRef]

136. Wu, X.; Hu, Y.; Ruan, M.; Madiomanana, N.K.; Hankinson, J.; Sprinkle, M.; Berger, C.; De Heer, W.A. Half integer quantum Hall effect in high mobility single layer epitaxial graphene. Appl. Phys. Lett. 2009, 95, 19912. [CrossRef]

137. Forbeaux, I.; Themlin, J.-M.; Debever, J.-M. Heteroepitaxial graphite on $6 \mathrm{H}-\mathrm{SiC}(0001)$ : Interface formation through conductionband electronic structure. Phys. Rev. B 1998, 58, 16396. [CrossRef]

138. Ciuk, T.; Caban, P.; Strupinski, W. Charge carrier concentration and offset voltage in quasi-free-standing monolayer chemical vapor deposition graphene on SiC. Carbon 2016, 101, 431-438. [CrossRef]

139. Bianco, F.; Perenzoni, D.; Convertino, D.; Bonis, S.L.D.; Spirito, D.; Perenzoni, M.; Coletti, C.; Vitiello, M.S.; Tredicucci, A. Terahertz detection by epitaxial-graphene field-effect-transistors on silicon carbide. Appl. Phys. Lett. 2015, 107, 131104. [CrossRef]

140. Qin, H.; Sun, J.; Liang, S.; Li, X.; Yang, X.; He, Z.; Yu, C.; Feng, Z. Room-temperature, low-impedance and high-sensitivity terahertz direct detector based on bilayer graphene field-effect transistor. Carbon 2017, 116, 760-765. [CrossRef]

141. GK, R.M.; Deshmukh, P.; Prabhu, S.S.; Basu, P.K. Antenna coupled graphene-FET as ultra-sensitive room temperature broadband THz detector. AIP Adv. 2018, 8, 125122. [CrossRef]

142. Güttinger, J.; Molitor, F.; Stampfer, C.; Schnez, S.; Ensslin, K. Transport through graphene quantum dots. Rep. Prog. Phys. 2012, 75, 126502. [CrossRef] [PubMed] 
143. Fatimy, A.E.; Nath, A.; Kong, B.D.; Boyd, A.K.; Barbara, P. Ultra-broadband photodetectors based on epitaxial graphene quantum dots. Nanophotonics 2017, 7, 735-740. [CrossRef]

144. Zhang, J.; Lin, L.; Jia, K.; Sun, L.; Peng, H.; Liu, Z. Controlled Growth of Single-Crystal Graphene Films. Adv. Mater. 2020, 32, 1903266. [CrossRef] [PubMed]

145. Yang, X.; Zhang, G.; Prakash, J.; Chen, Z.; Sun, S. Chemical vapour deposition of graphene: Layer control, the transfer process, characterisation, and related applications. Int. Rev. Phys. Chem. 2019, 38, 149-199. [CrossRef]

146. Kumar, S.; Mcevoy, N.; Kim, H.Y.; Lee, K.; Duesberg, G.S. CVD growth and processing of graphene for electronic applications. Phys. Status Solidi (b) 2011, 248, 2604-2608. [CrossRef]

147. Reddy, D.; Register, L.F.; Carpenter, G.D.; Banerjee, S.K. Graphene field-effect transistors. J. Phys. D Appl. Phys. $2011,44,313001$. [CrossRef]

148. Donchev, E.; Pang, J.S.; Gammon, P.M.; Centeno, A.; Xie, F.; Petrov, P.K.; Breeze, J.D.; Ryan, M.P.; Riley, D.J.; McN, N. The rectenna device: From theory to practice (a review). MRS Energy Sustain. 2014, 1, 1. [CrossRef]

149. Zhong, H.; Zhang, Z.; Chen, B.; Xu, H.; Yu, D.; Huang, L.; Peng, L. Realization of low contact resistance close to theoretical limit in graphene transistors. Nano Res. 2015, 8, 1669-1679. [CrossRef]

150. Ponomarenko, L.A.; Yang, R.; Mohiuddin, T.M.; Katsnelson, M.I.; Novoselov, K.S.; Morozov, S.V.; Zhukov, A.A.; Schedin, F.; Hill, E.W.; Geim, A.K. Effect of a High-\$ $\backslash$ ensuremath $\backslash \backslash$ kappa\}\$ Environment on Charge Carrier Mobility in Graphene. Phys. Rev. Lett. 2009, 102, 206603. [CrossRef]

151. Lei, L.; Bai, J.; Qu, Y.; Yu, H.; Duan, X. Single-layer graphene on Al2O3/Si substrate: Better contrast and higher performance of graphene transistors. Nanotechnology 2010, 21, 015705.

152. Regan, W.; Alem, N.; Alemán, B.; Geng, B.; Girit, Ç.; Maserati, L.; Wang, F.; Crommie, M.; Zettl, A. A direct transfer of layer-area graphene. Appl. Phys. Lett. 2010, 96, 113102. [CrossRef] 